\title{
درجة إسهام قائدات المرحلة الابتدائية \\ بالمدارس الحكومية بمدينة جدة في تنمية \\ مواردها البشرية في ضوء رؤية المملكة 2030 (من وجهة نظر المعلمات والوكيلات) \\ عائشة بكر آدم فلاتة

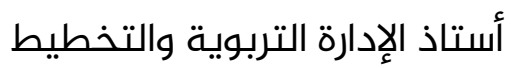 \\ كلية العلوم الصحية والسلوكية والتعليم \\ جامعة دار الحكمة- السعودية \\ حنان مـحمود سامهي أحمد عرب \\ ماجستير القيادة التربوية والسياسات التربوية والتقويم \\ جامعة دار الحكمة- السعودية \\ hananarab.sa@gmail.com
}




\title{
درجة إسهام قائدات المرحلة الابتدائية بالمدارس الحكومية بمدينة جدة في تنمية مواردها البشرية في ضوء رؤية المملكة 2030 (من وجهة نظر المعلمات والوكيلات)
}

\author{
حنان محمود سـامي أحمد عرب \\ ماجستير القيادة التربوية والسياسات التربوية والتقويم- جامعة دار الحكمة- السعودية
}

hananarab.sa@gmail.com

\section{عائشة بكر آدم فلاتة}

أستاذ الإدارة التربوية والتخطيط- كلية العلوم الصحية والسلوكية والتعليم- جامعة دار الحكمة- السعودية

DOI: https://doi.org/10.31559/EPS2021.10.2.12 2021/7/10 2021/6/2 مراجعة البحث: 2021/6/15 قبول البحث

\section{الملخخص:}

هدفت هذه الدراسـة إلى قياس درجة إسهام قائدات المرحلة الابتدائية بالمدارس الحكومية بمدينة جدة في تنمية مواردها البشرية، في ضوء رؤية المملكة 2030، من وجهة نظر المُعِلِّمات والوكيلات، واتبعت الدراسة المنهج الكمي الوصفي المسبحي، وطبَّقت الاستبانة أداة لجمع البيانات

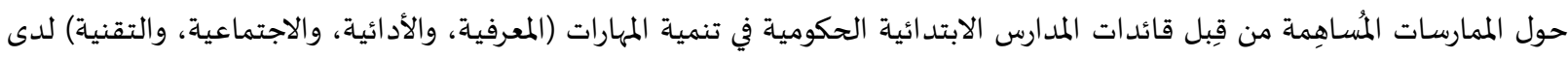

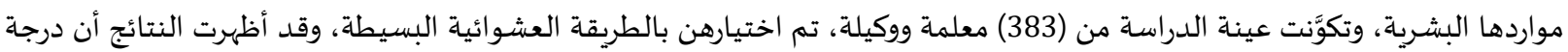
إسهام قائدات المرحلة الابتدائية في تنمية مواردها البشرية، من وجهة نظر أفراد العينة، جاءت بدرجة موافقة (مرتفعة) بمتوسط حسابي (3,96) وبنسبة مئوية (79.2\%)، وعدم وجود فروق ذات دلالة إحصائية في متوسط استجابات أفراد العينة لمحاور الدراسة.

ومن أبرز التوصيات التي توصلت إليها الدراسة: تعزيز وضع تنمية المهارات الأدائية للموارد البشرية من قِبل القيادات المدرسية؛ من خلال

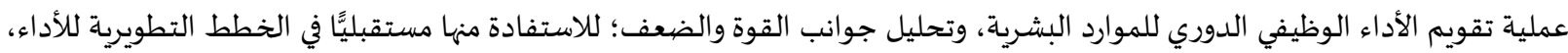

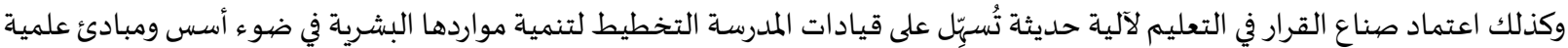
دقيقة وواضحةة، بما يساهم في تحقيق الغاية من التنمية المهننية بدقةٍة، بعيدًا عن العشوائية. الكلمات المفتاحية: القيادة التربوية؛ إدارة؛ أنماط القيادة الحديثة؛ النمو المهني.

لا شك أن مفهوم "تنمية الموارد البشرية" قد مرّ بمراحل عديدة منذ نشأته في مطلع التسعينيات من القرن الماضي إلى وقتنا الحاضير، وتجسَّد هذا التطور في البدء بالنمو الاقتصادي وصولًا إلى التنمية البشرية، باعتبار الموارد البشرية هي غاية التنمية وهدفها الأساسي. وبالنظر إلى مفهوم "تنمية

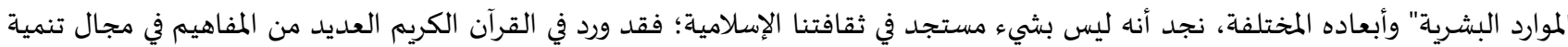
الموارد البشرية بصورة غير مباشرة، ولكن بشمولية وعمق ليس لهما مثيل؛ فقد اهتم الإسلام بالعنصر البشري، وأضاف لله قيمة روحية، وجسدية،

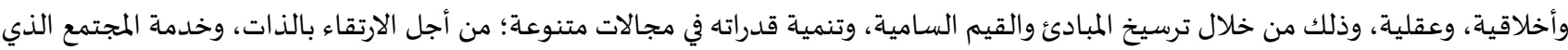




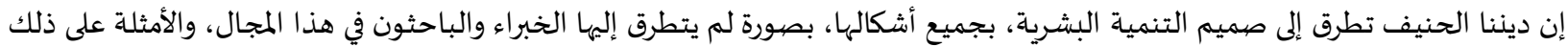

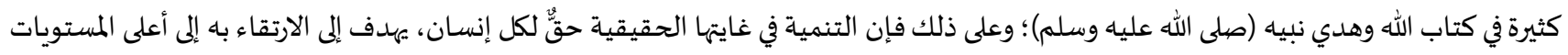

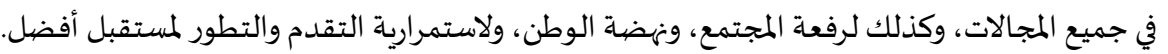

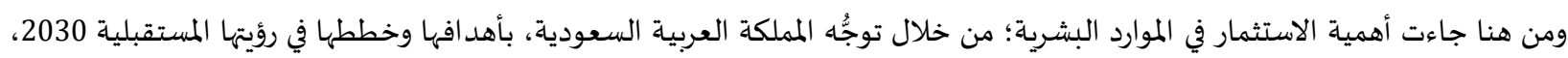

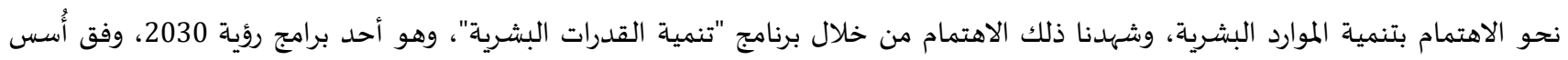

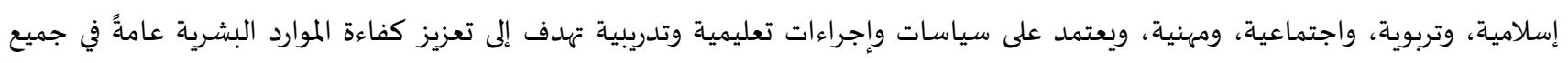

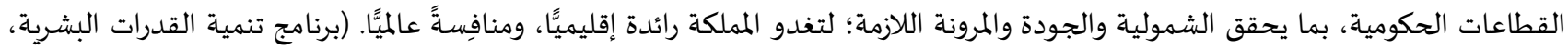

(2016

وبما أن التعليم في السعودية يشهد تقدمًا مذهلًا، تجسد في دور القيادات داخل المؤسسات التربوية، والتي هي أهم عامل في تنمية مواردها

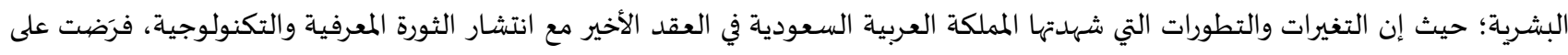

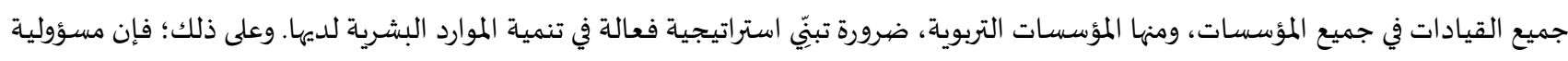

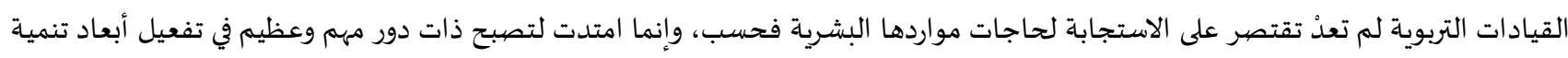

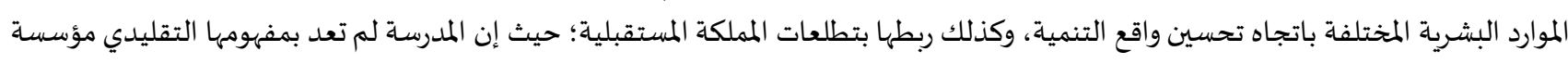

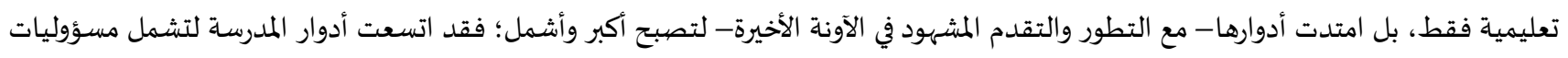

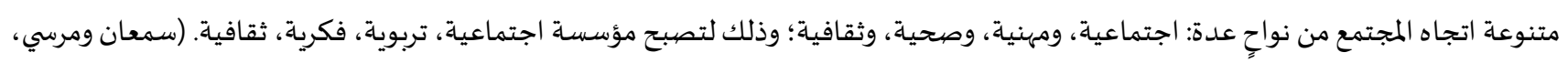

$(1985$

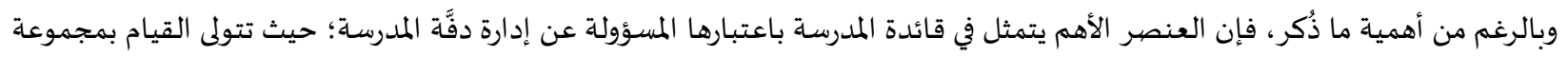

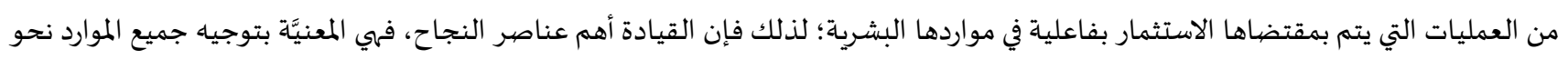

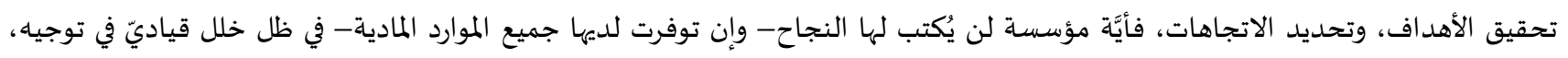

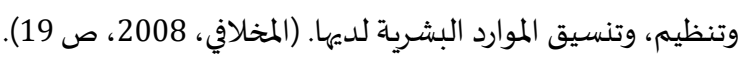

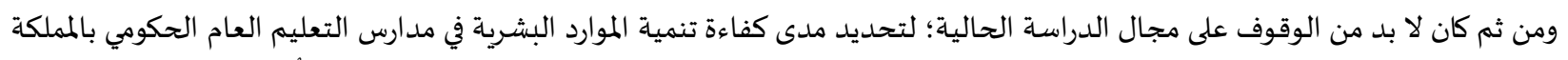

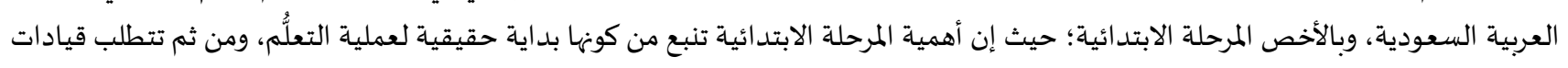

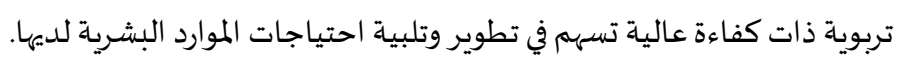

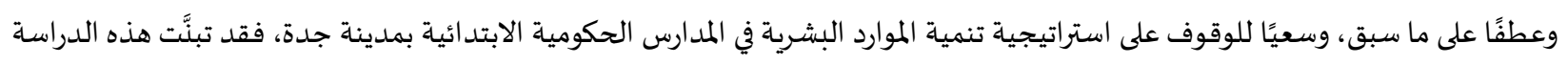

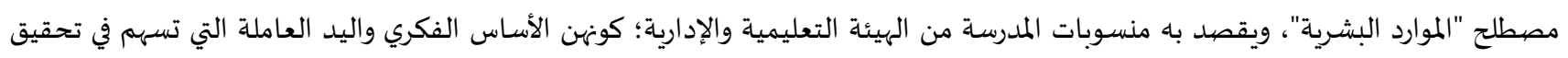

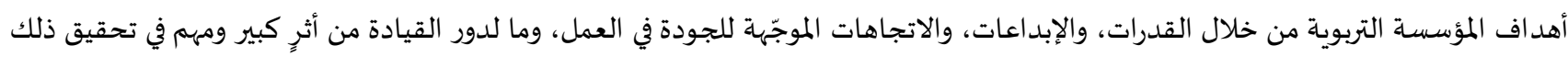

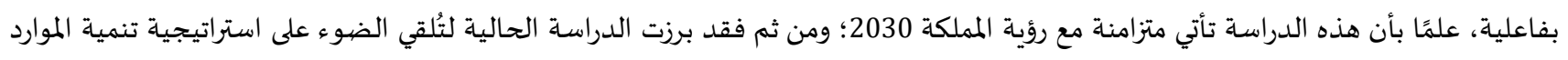

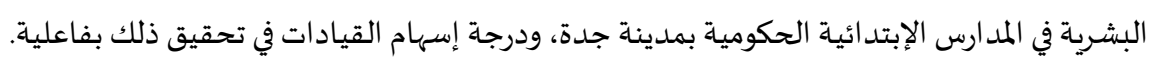

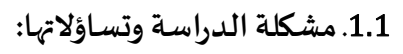

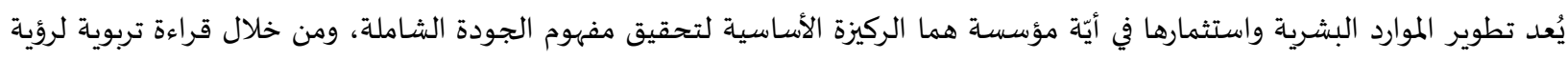

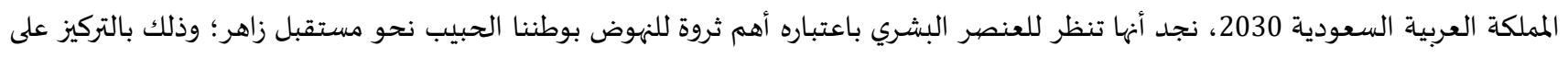

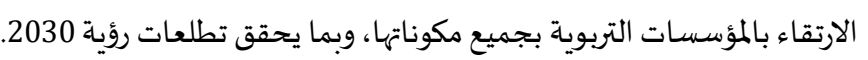

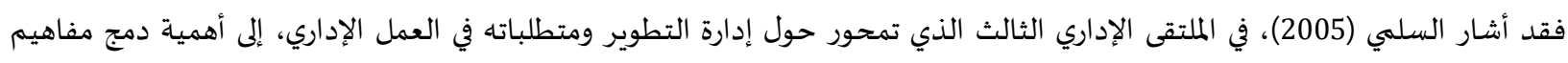

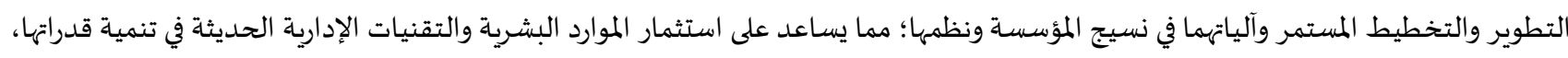
وتميُّها في مجالها.

وتتفق دراسة السرحان (2014) مع ما سبق الإثارة إليه من أن هناك علاقة تبادلية بين بناء مجتمع المعرفة وتحقيق تنمية بشرية مستدامة المقاء

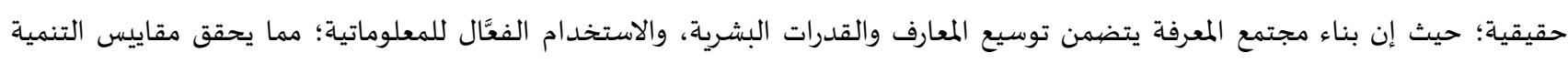

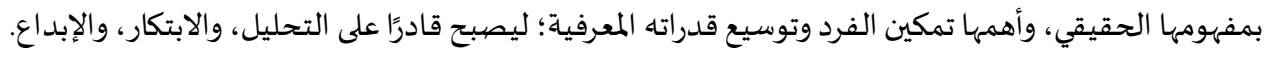

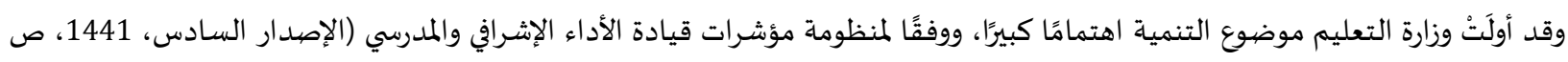

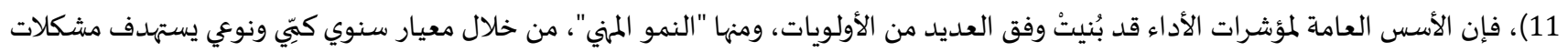

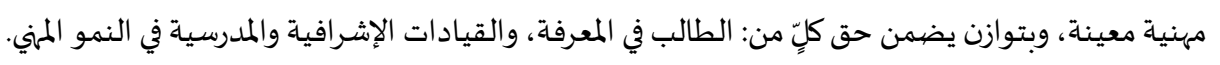


وعلى ذلك، فقد نصت خطة التنمية التاسعة لتنمية الموارد البشرية (1438، ص 376) في سياستها لتطوير النظم الإدارية ومكوناتها، على ضرورة

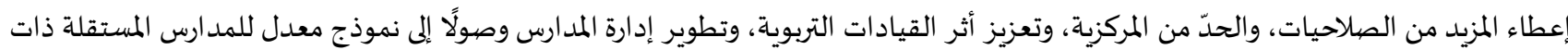

ومن خلال عمل الباحثة بالمدارس الحكومية، وإججرَائها مقابلات حرَّة (غير مقننة) مع بعض المعلمات والإداريات في مجال هذه الدراسة، بغرض إندات تشخيص الواقع وتدوين الملحوظات عن الممارسات القيادية المتبعة في تنمية الموارد البشرية داخل المدرسة؛؛ لاحظت الباحثة تبائن الآراء في فاعلية دور

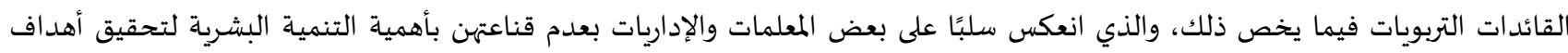

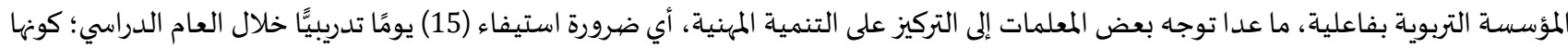

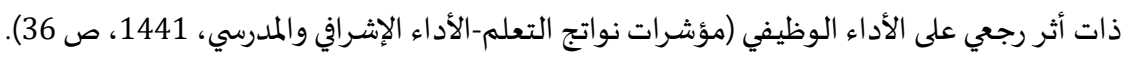

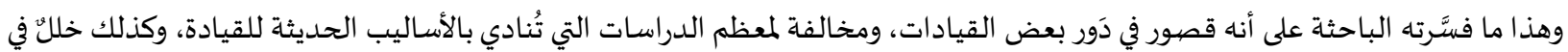

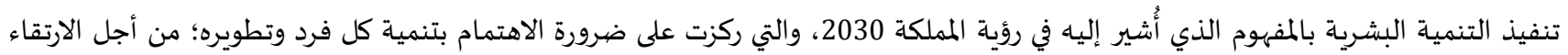
بالمنظمة أو مؤسسة العمل. وقد يكون أحد أسباب القصور في دور القيادات التربوية في النواحي السابقة، ما أشارت إليه دراسـة المطيري (2015) من أنه بالرغم من الجهود

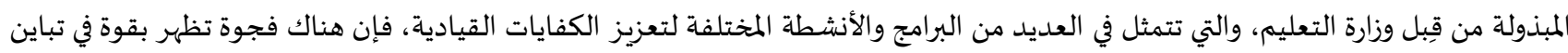
الأنماط القيادية، بل واستمرارية بعض القيادات التربوية في ممارسة الأنماط التقليدية.

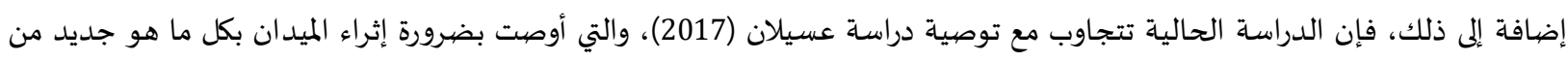

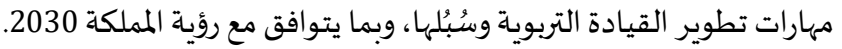

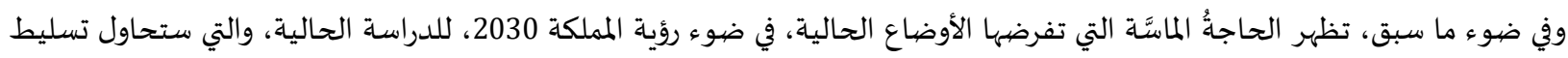

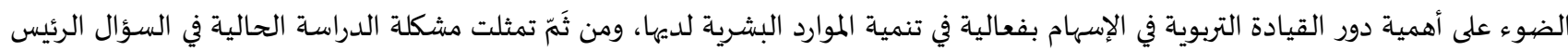

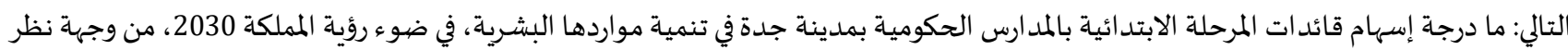
المعلمات والوكيلات؟ ما درجه ويتفرع من السؤال الرئيس الأسئلة الفرعية التالية:

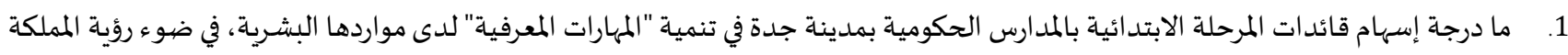

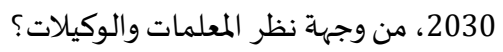

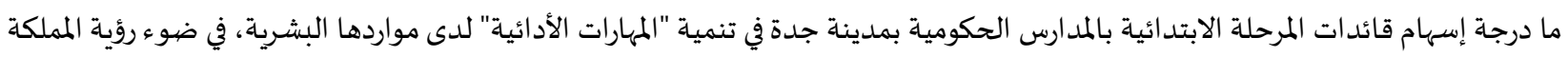

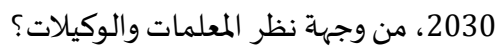

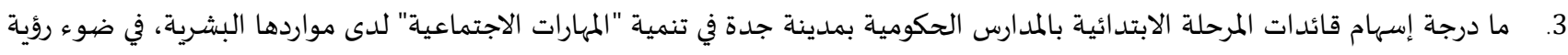

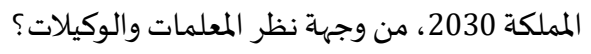

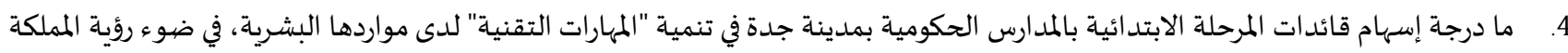
2030، من وجهة نظر المعلمات والوكيلات؟ مات دماته

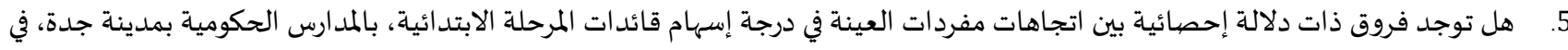

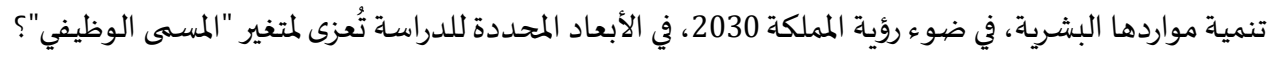

2.1 أهداف الدراسة:

تسعى الدراسة الحالية إلى:

1. الكشف عن درجة إسهام قائدات المرحلة الابتدائية بالمدارس الحكومية بمدينة جدة في تنمية "المهارات المعرفية"، و"المهارات الأدائية"، و"المهارات

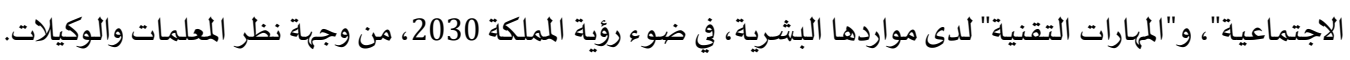

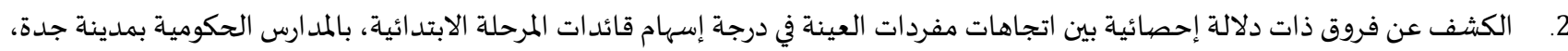

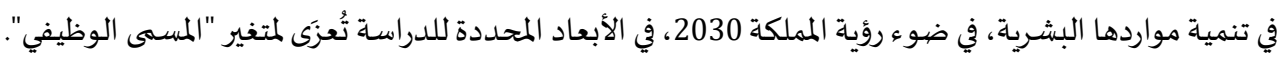

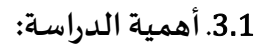

لهذه الدراسة أهمية نظرية وأخرى تطبيقية، ويمكن توضيح ذلك في التالي: 
الأهمية النظرية:

1. أنها تتناول موضوعًا مههًا يواكب أحدث الجهود المبذولة لتطوير التعليم العام في المملكة العبية السعودية، وتسعى سعيًا جادًا إلى تحقيق أحد

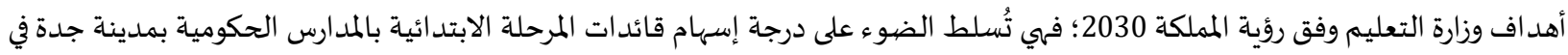

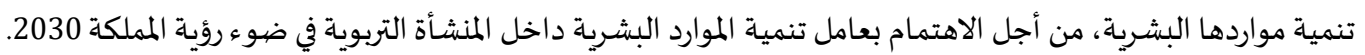

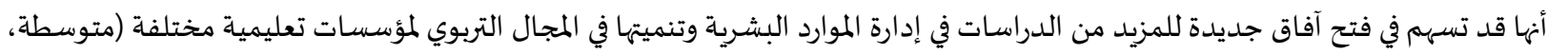

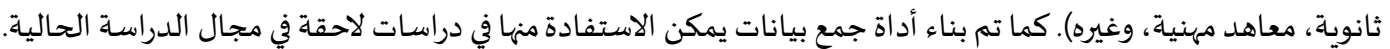

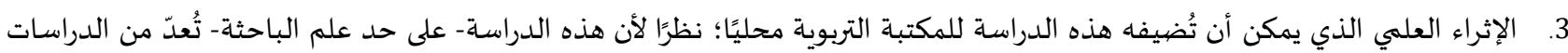
النادرة التي تطرقت إلى عامل تنمية الموارد البشرية في المجال التربوي بمد ارس التبعة التعليم العام الحكومي وفق رؤية المملكة 2030.

الأهمية التطبيقية:

1. قد تفيد هذه الدراسة المسؤولين في الإدارة التعليمية بمدينة جدة؛ من خلال قياس درجة إسهام قائدات المرحلة الابتدائية بالمدارس الحكومية في

تنمية مواردها البشرية، في ضوء رؤية المملكة 2030، وذلك بهدف تعزيز جوانب القوة لدى القائدات، وتطوير جوانب الضعف (إن وجدات). 2. يتوقع أن تُسهم نتائج هذه الدراسة في تقديم صهورة واقعية أمام صانعي القرار في وزارة التعليم، بصفية عامة، عن مستوى الممارسات القيادية

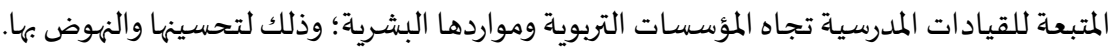

4.1. مصطلحات الدراسة:

قائدة المدرسة School Leader

1. التعريف اللغوي: يعرف ابن منظور (2000، ص 315) القيادة بصهة عامة بأها: "مشتقة من كلمة قاد، يقود، قودًا، فهو قائد، والقَوْدُ نقيض

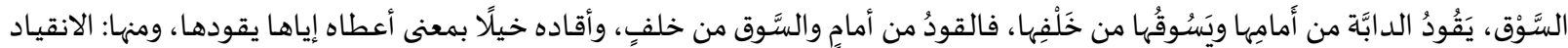
بمعنى الخضوع، ومنها: قادة، وهو جمع قائد".

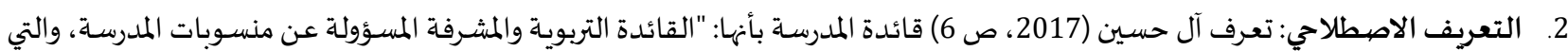

تقودها لتحقيق الأهداف المنشودة وفق السياسة التعليمياة للمدرساة".

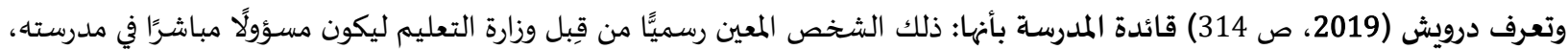
ومشرفًا على جميع شؤونها التربوية والإدارية والتعليمية والاجتماعية؛ لتحقيق بيئة تعليم جذابة، والتي تعمل أيضًا على تهيئة جميع الظروف والإمكانيات

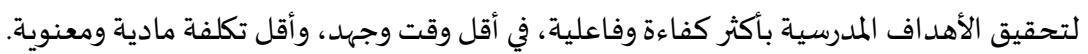
3. التعريف الإجر ائي: وتعرِّف الباحثة قائدة المدرسة إجر ائيًا بأنها: المسؤولة الأولى من الناحية الإدارية والفنية عن تيسير الأمور في المدرسة، ولها دور أساسي في تحسين العملية التربوية وتطويرها، والإشراف على شؤون الطالبات، وكذلك تنظيم ومتابعة وتنمية منسوبات المبات المدرسـة من

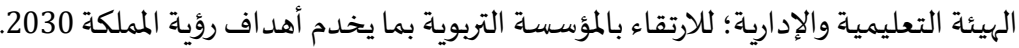

Human Resource Development تنمية الموارد البشرية

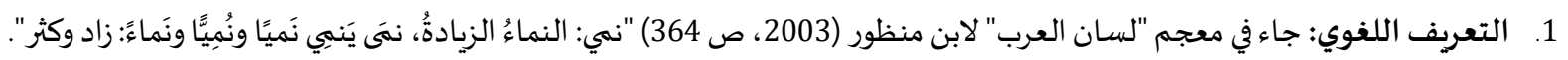

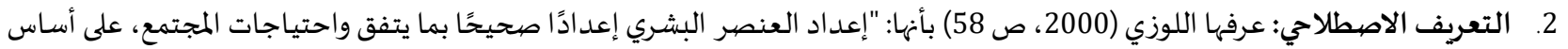
أنها بزيادة معرفة وقدرة الفرد يزداد ويطوّر استغلاله للموارد الطبيعية، فضلًا عن زيادة طاقاته وجهودهاه". 3. ويوافق التعريف السـابق تعريف أبي النصر (2009، ص 20) بأها: "عملية تهدف إلى توفير وإتاحة الفرصية المجتمعية والبيئية لنمو الطاقات

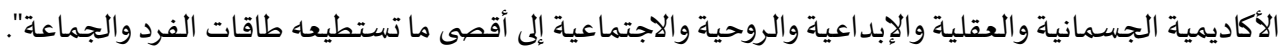

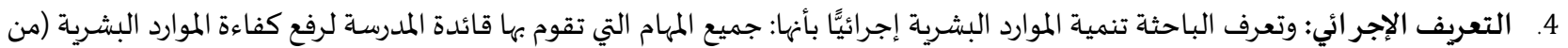

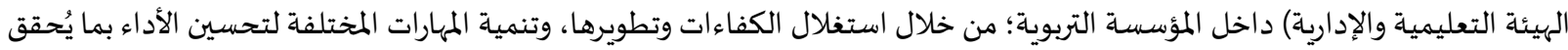
تطلعات رؤية المملكة 2030. م.1 تحدود الدراسـة:

• الحدود الموضيوعية: اقتصرت هذه الدراسة على قياس درجة إسهام قائدات المرحلة الابتدائية بالمدارس الحكومية بمدينة جدة في تنمية

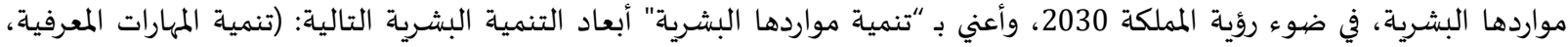

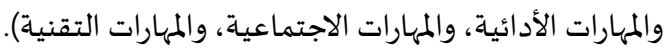
الحدود البشرية: اقتصرت هذه الدراسة على معلمات ووكيلات مدارس المرحلة الابتدائية بالمدارس الحكومية في مدينة جدة. 
الحدود المكانية: تم التطبيق ميدانيَّا على مدارس المرحلة الابتدائية الحكومية بمدينة جدة دون قُراها. الحدود الزمانية: تم تطبيق هذه الدراسة خلال الفصل الدراسي الثاني من العام الدراسي 1440-1441هـ.

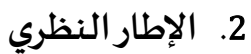

تضهمن هذا الجزء مبحثين أساسيين تم التطرق إلههما بالتفصيل، وبما يخدم هذه الدراسـة، وهما على النحو التالي:

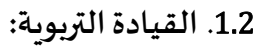

1.1.2. مفهوم القيادة التربوية:

تعد القيادة من أهم المجالات التي تم تداولها من قِبل الباحثين والخبراء من عدة جوانب، إلا أنه لم يتم الاتفاق على مفهوم محدد وشامل للقيادة،

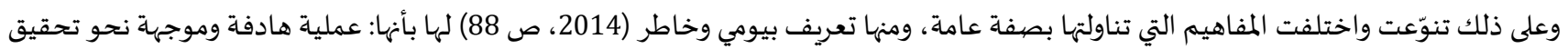

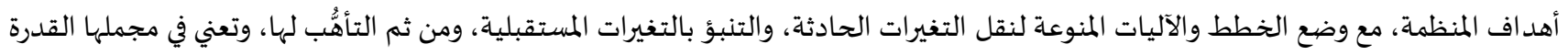
على التأثير في الآخرين أو في منظمتهم، ومن ثم توجيههم من الداخل، أو نقل التوجيه الخارجي من خلال عقد شراكات مع مؤسسة متخصصية للمساعدة في تجويد الأداء، وزيادة الإنتاجية.

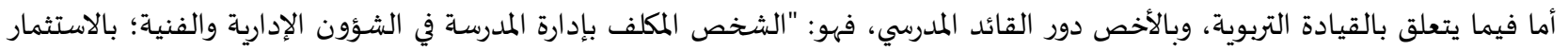

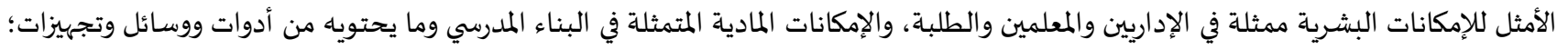

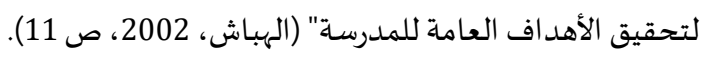
وقد أشارت وزارة التعليم بالمملكة العربية السعودية في الدليل التنظيهي لمدارس التعليم العام (الإصدار الرابع، 1440، ص 34) إلى: "أن قائد

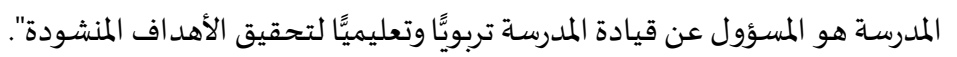

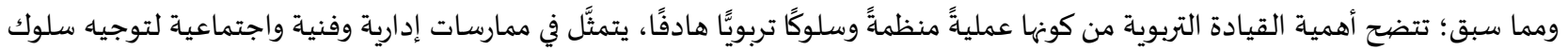

الموارد البشرية في المدرسة، وتحفيزهم لإنجاز المهام بطريقة مبتكرة وإبداعية، ولتحقيق أهداف المؤسسة التربوية في ضوء الرؤية المستقبلية للمملكة.

2.1.2 أهمية القيادة التربوية:

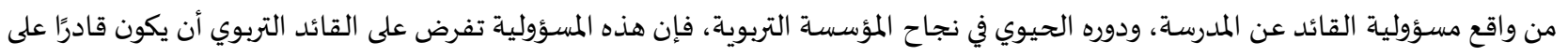

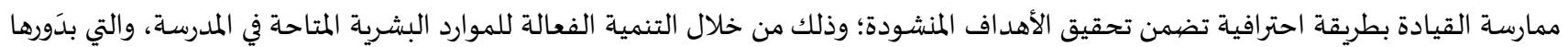
تحقق الانسجام المطلوب لتأدية العمل بأفضل الإمكانيات، وبجودة عادية عالية.

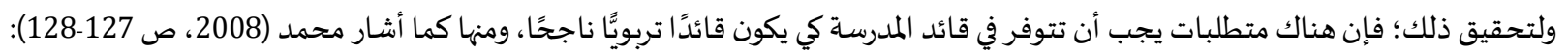
البعد عن المركزية، والاتجاه نحو القيادة الرشيدة التشاركية. إعطاء الحرية الفكرية، واحترام آراء العاملين وأخذها بعين الاعتبار في خدمة مصلحة العهة العمل. منح مدير المدرسة المزيد من الصلاحيات في حدود نطاق مدرستها. تشجيع الأعمال الإبداعية والأفكار الصحيحة؛؛ للتأكيد على الشعور بالأمن والطمأنينة.

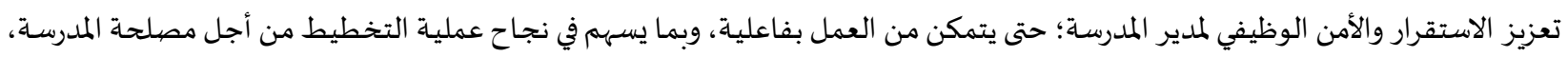

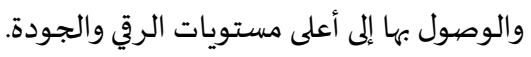

اتباع المناهج الديمقراطية الحديثة في قيادة المدرسة، والبعد عن النمط التقليدي التسلطي. العمل على توفير منشأة تعليمية سليمة وبيئة إيجابية مُحفِّزة للموارد البشرية في المدرسية. القدرة على التأثير على الأفراد بالمدرسة وتوجياء سلوكهم، ورسم الخطط وتوزيع المهام حسب الكفاءة والاستعداد البشري والمادي المتاح، أي توجياه

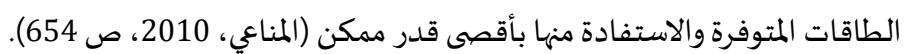
من خلال ما سبق، يتضح أن القيادة التربوية بمفهومها الحديث تعد جوهر عمل القائد المدرسي الذي يسههم في إثارة اهتمام موارده البشرية، واستثمار طاقاتهم، وتنسيق جهودهم، وتنظيم أعمالهم؛ من أجل تحقيق الأهداف المرجوة.

3.1.2 أهداف القيادة التربوية: إن القيادة لا يمكن أن تكون ناجحة في حالة عشوائيةِ أهداف القائد واختلافها؛ لذا فإن القيادة الفاعلة هي التي تقوم بتوحيد الأهداف، وخلق

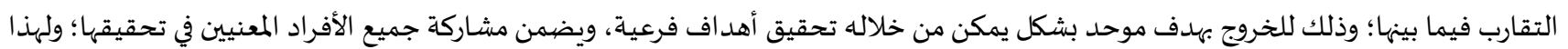

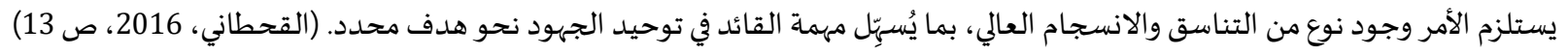


والقيادة الناضجة تنطلق في ممارساتها القيادية لتحقيق أهداف معينة؛ لذلك فإن القيادة عملية تقوم على التوجيه والتنظيم والتنسيق، فقد أشار البدري (2001) إلى أن القيادة التربوية تقوم على سمات تتمثل في عدد من العمليات القيادياة، وهي كالتالي: عملية إنسانية في المقام الأول تهدف جاهدةً إلى إشباع حاجات وميول الأفراد. عملية جماعية تعاونية، أي إنها مشتركة، فهي تُسههم في تميُّز المؤسسة التربوية وتقدُّهها من خلال التعاون والتفاهم المتبادل. عملية منظمة، فهي تتم وفق أهد اف محددة، وجهود مدروسة بعناية، وتنظيم للأنشطة المُمارَسة جميعها تحت إشراف المؤسسة التربوية.

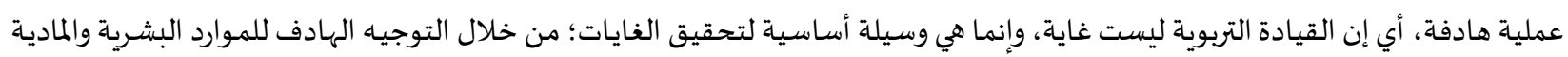
نحو تحقيق أهداف المؤسسة التربوية. من خلال ما سبق، يتضح أن تحقيق أهداف القيادة بنجاح يتطلب اختيار قيادات تربوية وفق معايير عالية من كفاءات ومؤهلات عليا، وأيضًا وفق

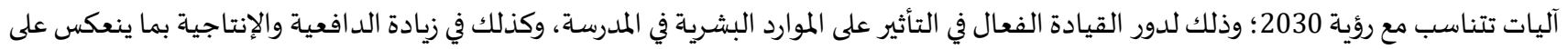
رقي وتميز المؤسسة التربوية.

4.1.2 أنماط القيادة التربوية:

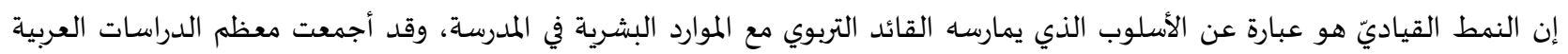

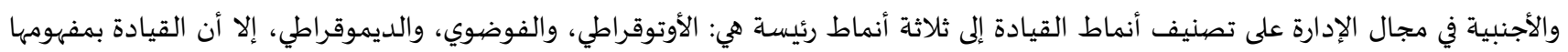

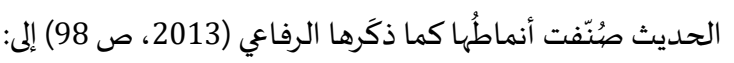
القيادة الموقفية: وهي نمط قيادي يعتمد على قدرة القائد على تغيير نمطه وفق الموقف الذي يواجهاه، وطبيعة الأفراد المحيطين باه، والبيئة المدرسية، أي إن أسلوب

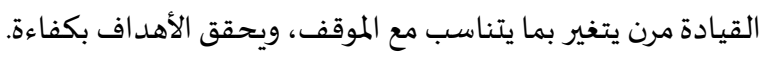
القيادة التحويلية: وهي من الأنماط الجديدة والأكثر شهرة مقارنةً بأنماط أخرى، وتقوم على القيادة بفاعلية من أجل إحداث تغيير، وضمان الاستمرارية؛ من خلال

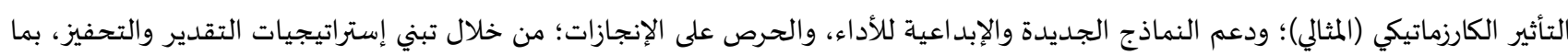
يحقق الجودة في العمل. القيادة التشاركية: وهي نمط قيادي قائم على المشاركة، ويقوم على التشاور والتعاون والشراكة الفعلية في اتخاذ القرار بين القائد والموارد البشرية لديه في المدرسة، بما يحقق أهداف المؤسسة التربوية.

القيادة الإبداعية: وهي نمط قيادي يعتمد على قدرة القائد على تغيير أو استحداث أسلوب أو نهج جديد، واستخداماه بتقنيات حديثة؛ لتحقيق أعلى معايير الجودة

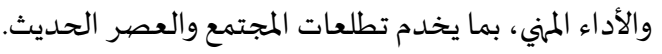

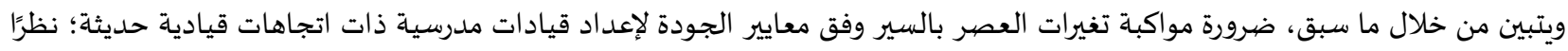

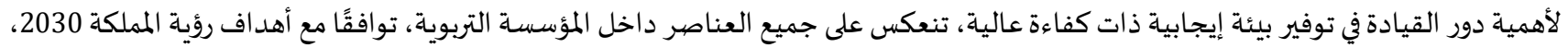

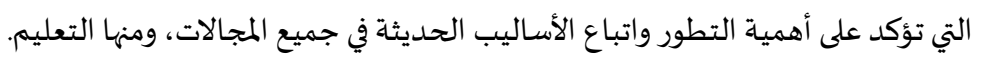

2.2. تنمية الموارد البشرية:

1.2.2. مفهوم إدارة وتنمية الموارد البشرية:

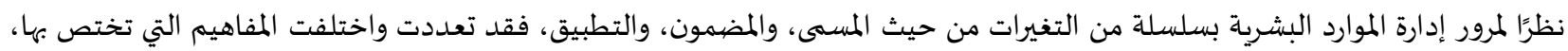

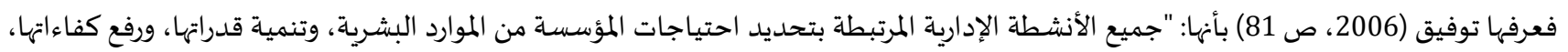
ومنها: التعويض، والتحفيز، والرعاية الكاملة؛ بهدف الاستفادة القصوى من جهدها وفكرها من أجل تحقيق أهداف المؤسسة".

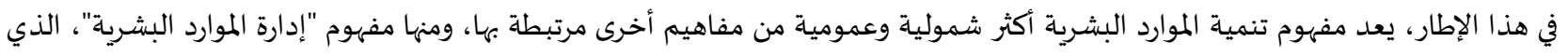

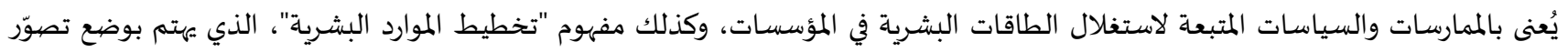

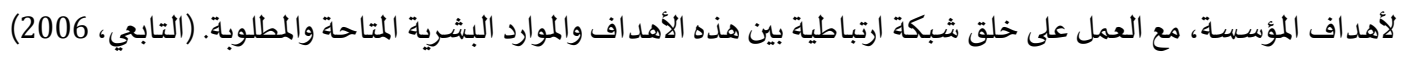

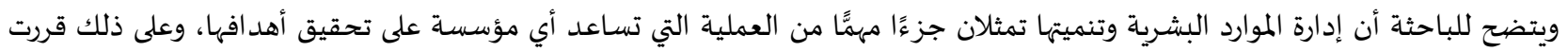

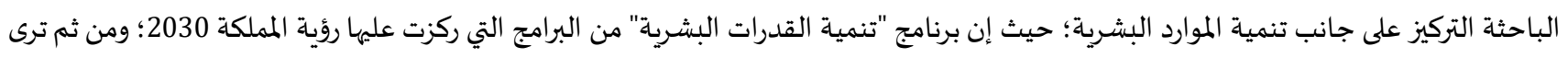


الباحثة أن تنمية الموارد البشرية في المؤسسة التربوية تعد إحدى أهم الوظائف لكل قائد تربوي مواكب للتطورات الحديثة، فهي تهتم بالممارسات

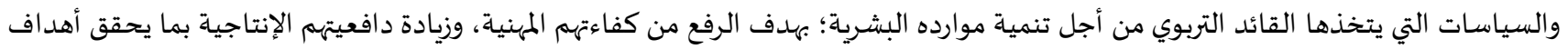

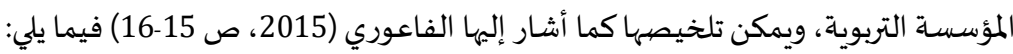

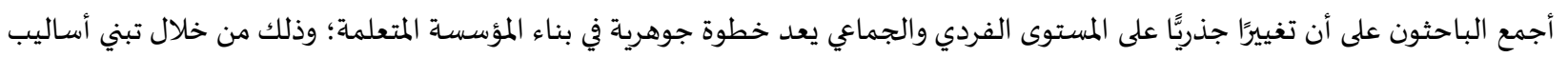
وأنماط قيادية حديثة تتناسب مع الرؤى القادمة.

أن الباحثين درسوا واقع المؤسسات من زوايا حديثة متعددة؛ فمنهم من ركّز على المعايير والأساليب التي يجب تطبيقها لبناء مؤسسة متعلمة،

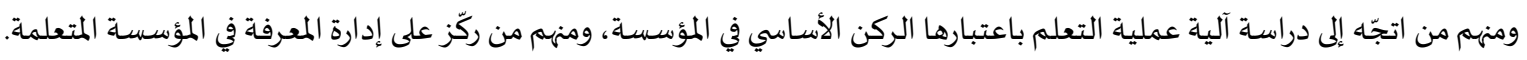

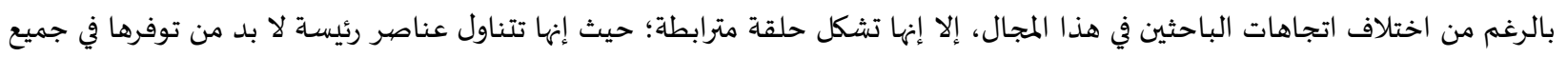

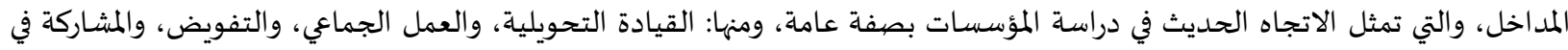
صنع القرار، وجودة الأداء، والمناخ التنظيمي المناسب، ووضوح الأهداف، واستخدام التقنية والأساليب الحديثة في العمل، وما ولئ، إلى ذلك.

2.2.2 أهمية تنمية الموارد البشرية:

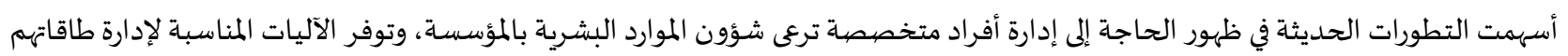

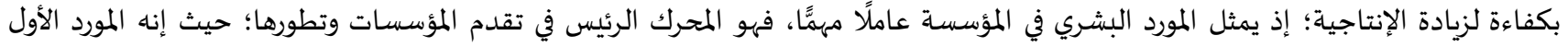

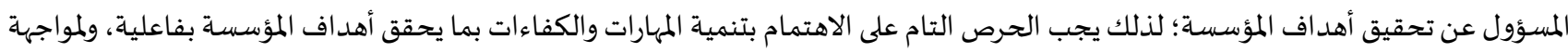
التحديات التي تعيق تطورها نحو الأفضل. (شلتوت، 2009، ص 3. 3)

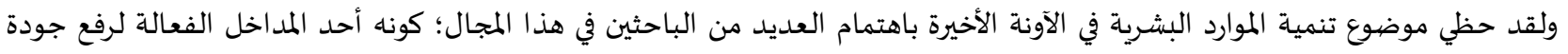

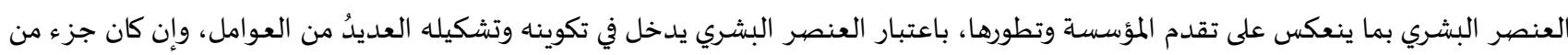

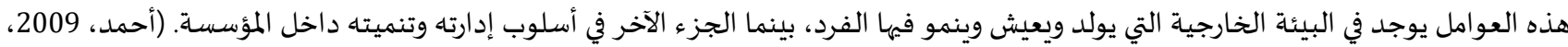

يتبين مما سبق أهمية المورد البشري في جميع المجالات، بصفة عامة، والمجال التربوي بصفة خاصةة؛ حيث إن كفاءة الموارد البشرية داخل

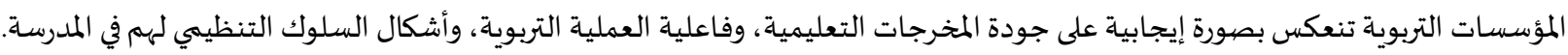
أهد اف تنمية الموارد البشرية.

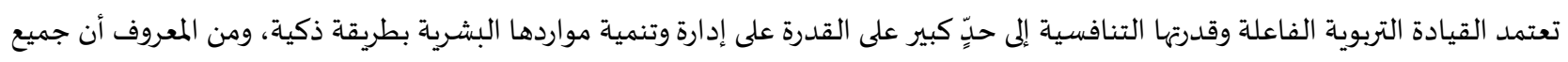
الأنشطة المتعلقة بالمؤسسة التربوية تعتمد إلى حد كبير على العنصر البشري؛ ولذلك لا بد من تطوير القدرات، والاستفادة المثلى من هذه الطاقات

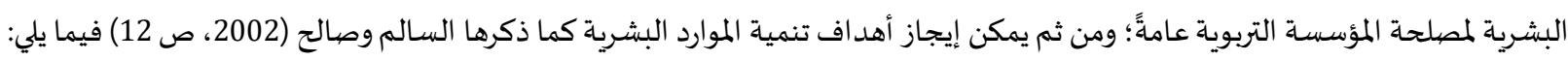
الاستفادة من جهود الموارد البشرية وخبراتهم في إنجاز المهام وفق المعايير المحددة سلفًا.

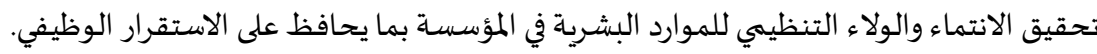
تنمية قدرات الموارد البشرية بتدريههم على مواجهة التغيرات التكنولوجية الإدارية.

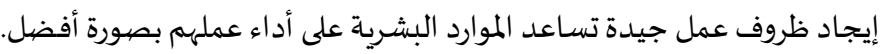
دعم فرص حصول الموارد البشرية على التقدم والرقي الوظيفي بتأهيلهم لذلك. تحديد احتياجات الموارد البشرية في المؤسسة، والعمل على تحقيقها؛ لدعم عملية الاستقرار الوظيفي. ويتضح مما سبق، أن أهداف تنمية الموارد البشرية تختلف باختلاف المؤسسة والقائد المسؤول؛ ولذلك يُنظر إلى القائد باعتباره شخصيًا لله دور أساسي وحيوي في تنمية الموارد البشرية لديه.

3.2.2 أبعاد تنمية الموارد البشرية:

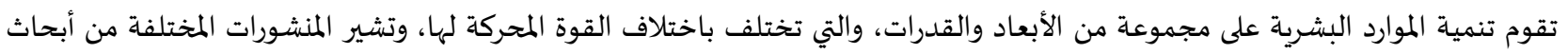

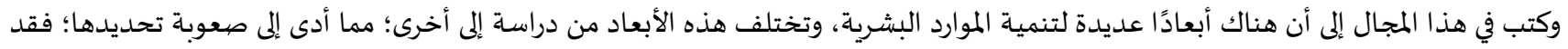

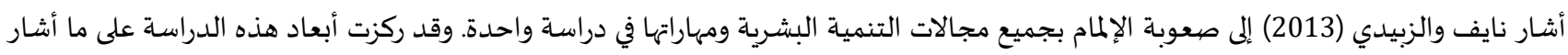

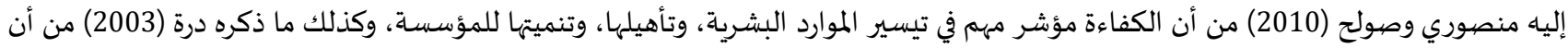

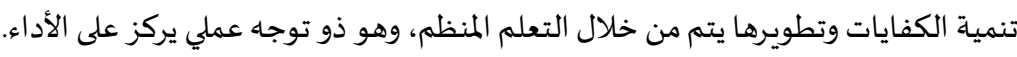

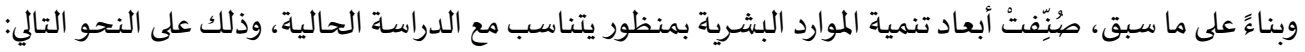


ت تنمية المهارات المعرفية:

تحتاج المعرفة إلى تنظيم المعلومات وإدارتها؛ لذلك فإن المعتهيه: العمل تحت إطار إدارة المعرفة يُمكّن من الاستغلال الأمثل للمهارات والخبرات، من خلال

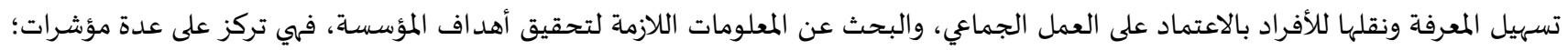

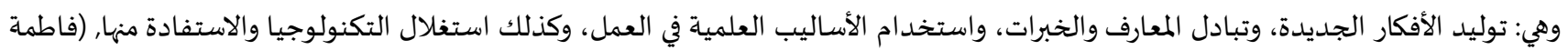

الزهراء وعرايبية، ونوين

\section{• تنمية المهارات الأدائية:}

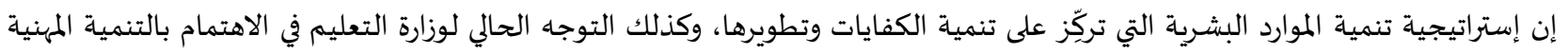

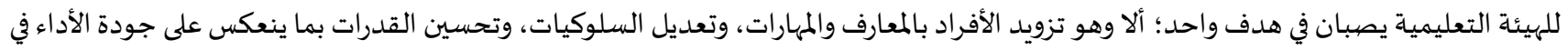
المؤسسة التربوية. وعلى ذلك؛ يعد هذا البعد من الأبعاد المهمة كونه ذا توجهاه مهني يُعنى بالمهارات الوظيفياة.

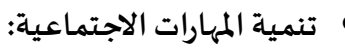

أكدت نظرية التنظيم الاجتماعي العلاقة القوية بين القيادة التربوية وممارسات المنظمة المتعلمة أو المدرسة المتعلمة؛؛ من خلال إسهام القيادة التربوية في تنمية المهارات البشرية لديها، وذلك بالحرص على نقل علم الفرد إلى المؤسسة عامةً. (صبري، 2013، ص 104)

تنمية المهارات التقنية:

من أهم المجالات التي تخدمها الدراسات والخطط التطويرية لرؤية المملكة 2030 ما نشهده من خطط للتحول الرقهي في جميع القطاعات، ومنها

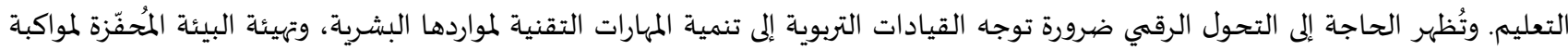

التطورات في المجال الرقهي، بما يخدم الارتقاء بالمؤسسات التربوية نحو مؤسسة داعمة لرؤيتنا المستقبلية وتحولنا الوطني.

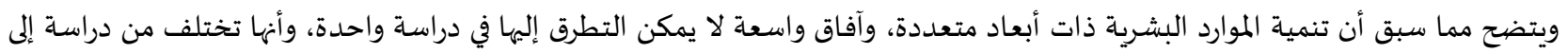
أخرى تبعًا للأهداف المراد تحقيقها من الدراسـة، وعلى ذلك رأت الباحثة تصنيف أبعاد هذه الدراسـة بناءً على ما تم الاطلاع عليه في أدبيات الدراسات السابقة، وما يخدم الدراسة الحالية.

4.2.2 تنمية الموارد البشرية وعلاقتها برؤية 2030:

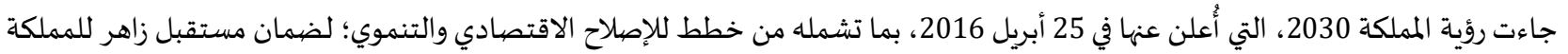

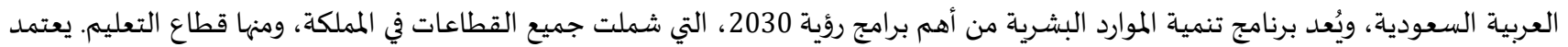

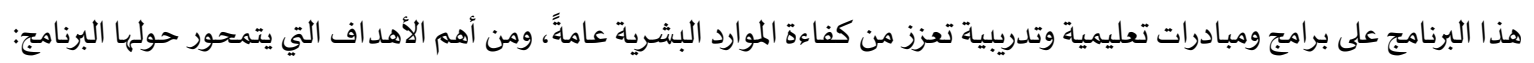
الاهتمام بالتعليم والتطوير المستمر (التعلم مدى الحياة). التوسع في التدريب المهن بما يحقق احتياجات سوق العمل. تمكين الأفراد من الحصول على التدريب المناسب، وتعزيز المهارات اللازمة لتسهيل الاندماج في سوق العمل. زيادة عدد فرص اكتساب الخبرات على رأس العمل. توفير برامج متنوعة عملية ومرنة. (الرويس، 2018) وفي ضوء ما سبق، يمكن ملاحظة مدى تركيز الرؤية على العنصر البشري كعنصر أسـاسي للتقدم الحضاري والعلمي، ومن ثم لا بد من مواكبة هذه

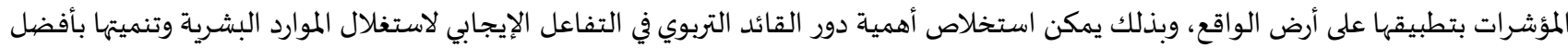
طريقة ممكنة؛ للانتقال من نماذج المدارس التقليدية إلى نماذج المدارس الرائدة في التعليم، والتي تتوافق مع أهدافئ أهداف رؤيتنا المستقبلية وتحولنا الوطني. 3.2. الدراسات السابقة: تضمن هذا الجزء عرضيًا للدراسات السابقة المحلية والعربية والأجنبية ذات الصلة بموضوع الدراسة الحالية، التي توصلت إلهها الباحثة باستخدام مصادر المعلومات التقليدية والإلكترونية، وعُرضت وفق التسلسة التسل الزمني من الأقدم إلى الأحدث، مشتملة على معلومات عن الدراسـة، وأهدافها،

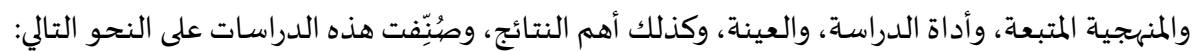

أولاً: دراسات مرتبطة بالقيادة التربوية:

دراسة إقبال (Iqbal, 2012) وهي بعنوان "استر اتيجية تحسين المهارات القيادية لمديري المدارس في محافظة خيبر باختانخوا". هدفت هذه الدراسة إلى التعرف على المهارات القيادية الممارسة من قِبل مديري المدارس في محافظة خيبر باختانخوا الباكستانية، وكذلك وضعع إستراتيجية

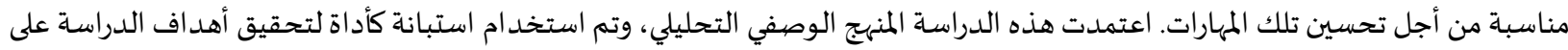


عينة من (20) مديرًا، و(40) معلمًا، اختيروا اختيارًا عشوائيًا بسيطًا من مجتمع الدراسة. وقد توصلت الدراسة إلى عدة نتائج، أهمها: أن المديرين

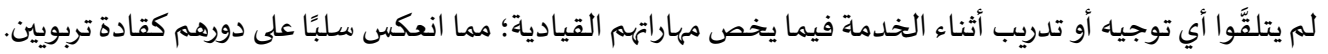
دراسة الغامدي (2013)، وهي بعنوان "درجة جودة أداء القيادة التربوية وتنمية الموارد البشرية في المدارس الثانوية والمتوسطة بالمدينة المنورة". وهدفت هذه الدراسة إلى التعرف على جودة أداء القيادة التربوية وتنمية الموارد البشرية في مدارس البنين الثانوية والمتوسطة بادية بالمدينة

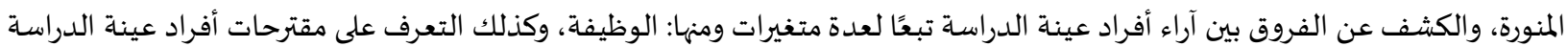
لرفع جودة أداء القيادة التربوية وتنمية الموارد البشرية في المدارس الثانوية والمتوسطة للبنين بالمدينة المنورة. اعتمدت هذه الدراسة المنهج

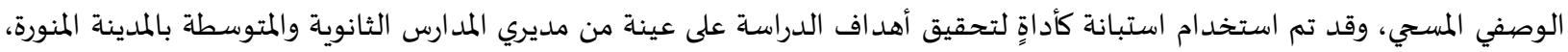

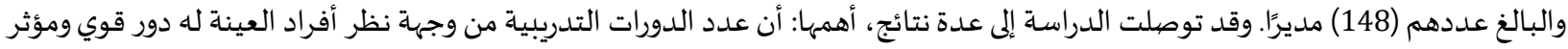

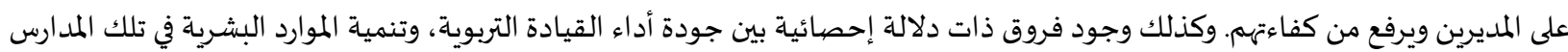

تعزى إلى متغير الوظيفة.

دراسة موثوني (Muthoni, 2015)، وهي بعنوان "كفاءة مديري المدارس الثانوية في إدارة الموارد البشرية: نماذج مدارس من مقاطعة ماثويا،

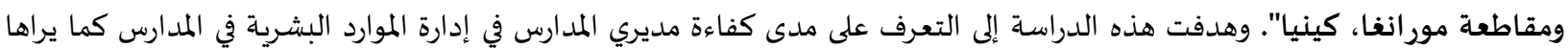

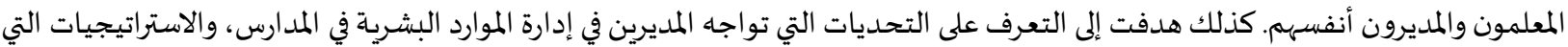
قد يستخدمها المديرون لضمان الكفاءة في دورهم. وقد اعتمدت هذه الدراسة المنهج الوصفي، واشتملت أدوات الدراسة على استبيانين: أحدهما للمديرين والآخر للمعلمين. وتكونت عينة الدراسة من (29) مديرًا و(174) معلمًا. وقد توصلت الدراسة إلى عدة نتائج، أهمها: عدم كفاءة مديري

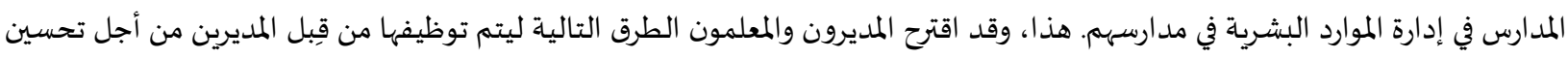

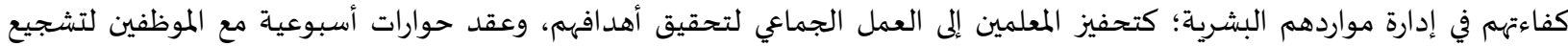
العلاقات الإنسانية.

دراسـة ميتارو (Mitaru, 2015)، وهي بعنوان "العو ائق التي تحول دون الإدارة الفعالة للموارد البشرية من قِبل مديري المدارس الابتدائية العامة: مقاطعة شرق الفرعية من مويا، ومقاطعة كيرينياغا، كينيا". وهدفت هذه الدراسة إلى تحديد العوائق التي تحول دون الإدارة الفعالة

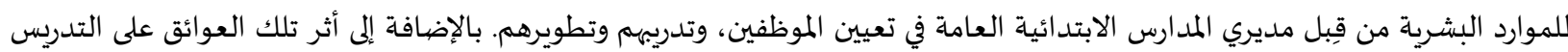
والتعلم في المدارس. والتعرف على الاستراتيجيات التي اعتمدها المديرون في المدارس الابتدائية العامة للحدد من التحديات المتعلقة بإدارة الموارد

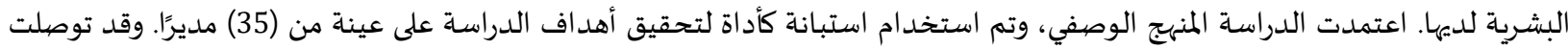

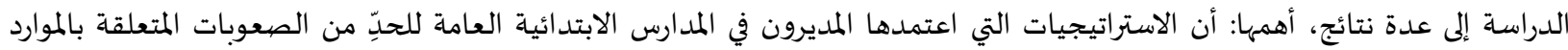

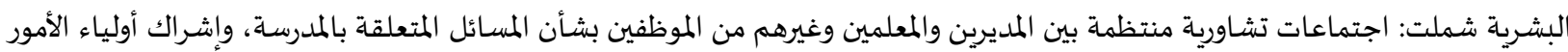

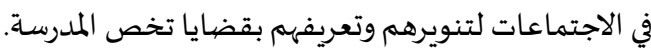

دراسة جولي (Jolley, 2016)، وهي بعنوان "القادة التحويليون: دراسة مختلطة الأساليب حول دور القيادة التحويلية و أثرها على فعالية المعلم". وهدفت هذه الدراسة إلى بحث العلاقة بين السلوكيات المحددة للقيادة التحويلية التي تتعلق بتعزيز الفاعلية الذاتية للمعلمين. وقد اعتمدت هذه الدراسة المنهج المختلط (الكمي والكيفي)، وهو منهج قائم على مقياس الفاعلية الذاتية لدى المعلمين مكون من (12) فقرة. تم استخدام استبانة ومقابلة كأداتين لتحقيق أهداف الدراسة، واشتملت الاستبانة على (10) فقرات لمعرفة رأي المعلمين في القيادة التحويلية، بالإضافة إلى المقابلات الشخصية مع المعلمين. طُبقت الأداتان على عدد من معلمي المراحل الابتدائية والمتوسطة والثانهانوية بمقاطعة مدانية مدرسية في جنوب شرق الولايات المتحدة الأمريكية. وقد توصلت الدراسة إلى عدة نتائج، أهمها: وجود علاقة إيجابية بين سلوكيات المهات القيادة التحويلية

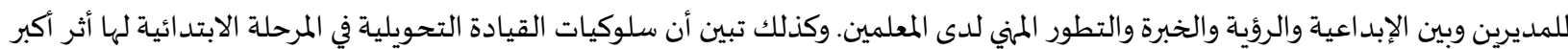

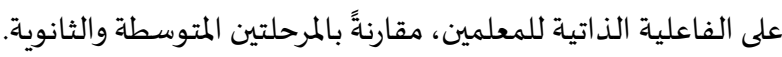

دراسة الحولي (2016)، وهي بعنوان "الاحتياجات التدريبية لمديري المدارس الحكومية في محافظات غزة في ضوء مجالات تنمية الموارد

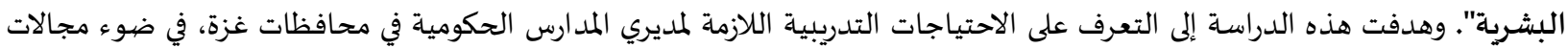

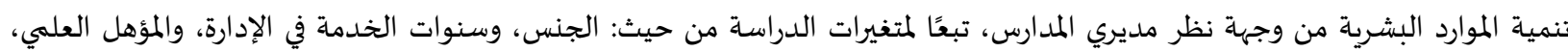

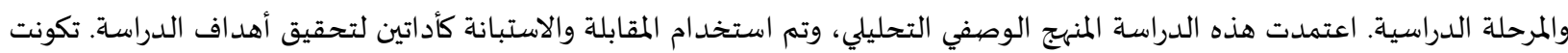

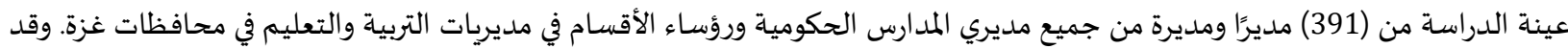

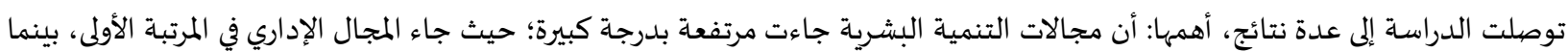
المجال التقني حل في المرتبة الأخيرة. 
دراسة إدربس وآخرين (Idrus et al. , 2017)، وهي بعنوان "ممارسات إدارة الموارد البشرية بين مديري المدارس الابتدائية: دراسة حالة

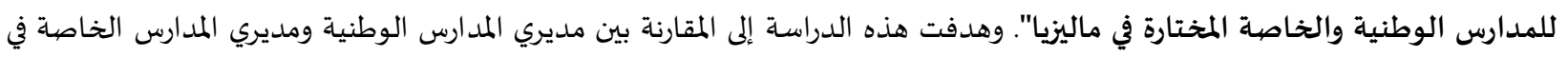

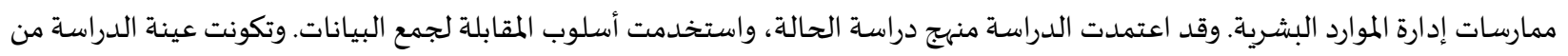

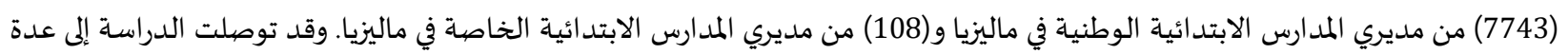

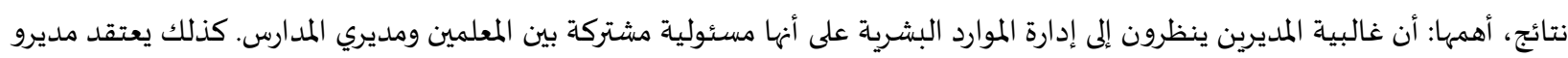

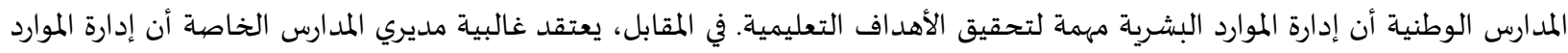

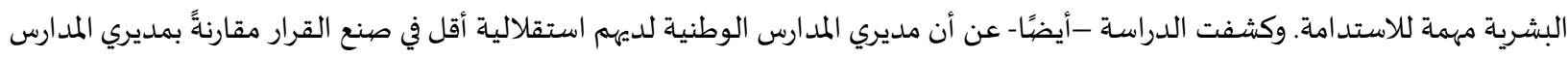

الخاصة.

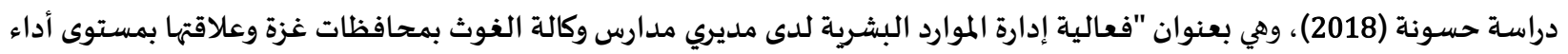

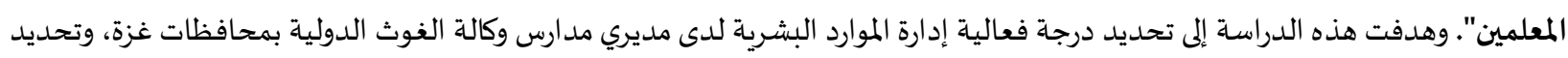

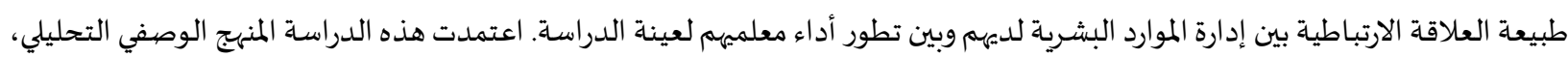

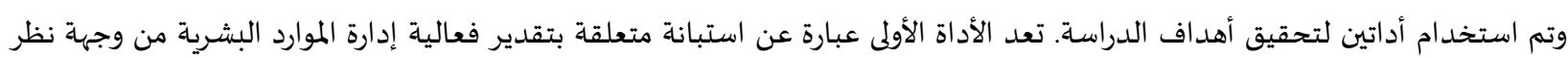

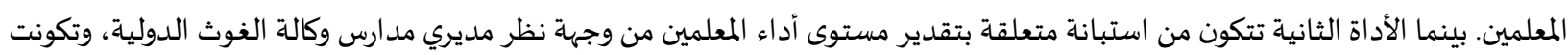

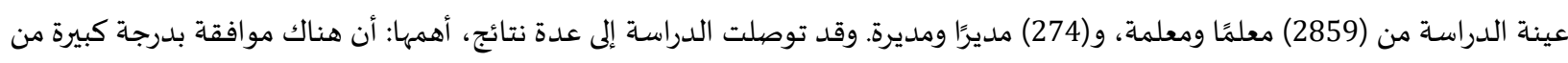

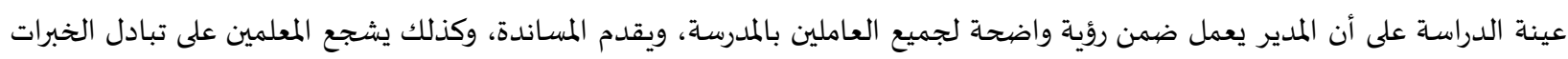
والعمل بروح الفريق.

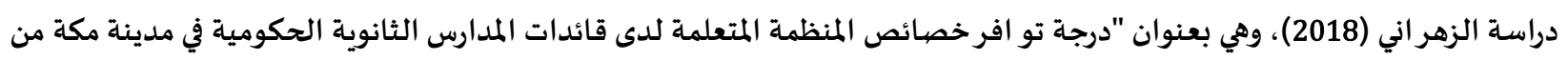

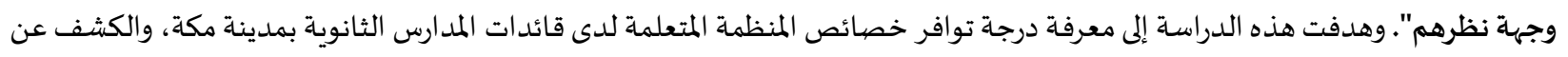

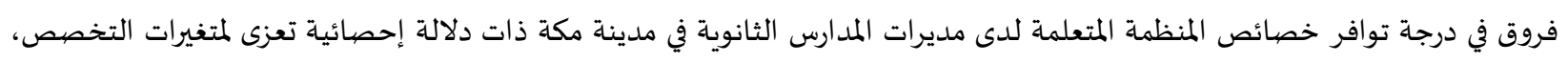

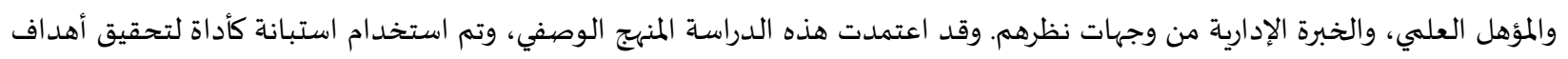

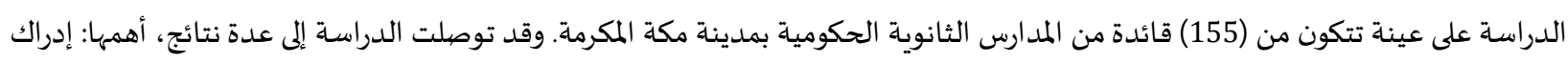

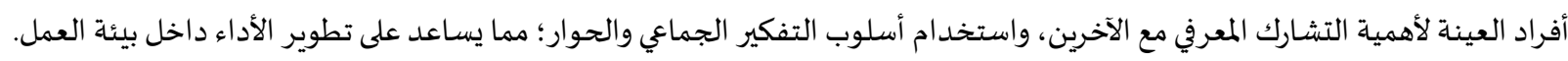

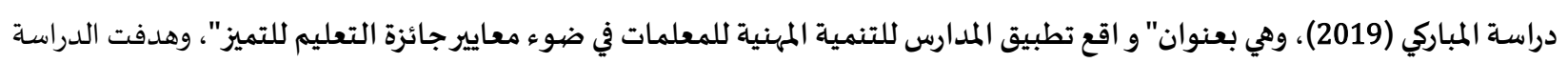

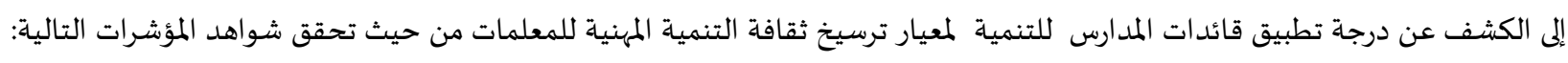

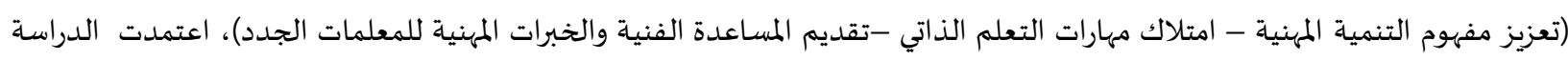

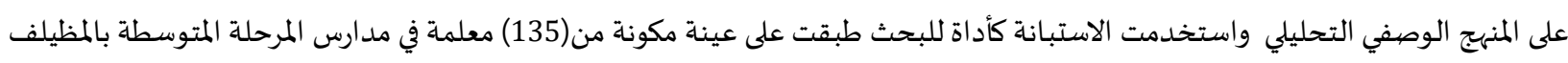

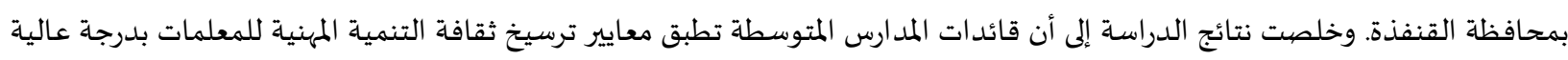

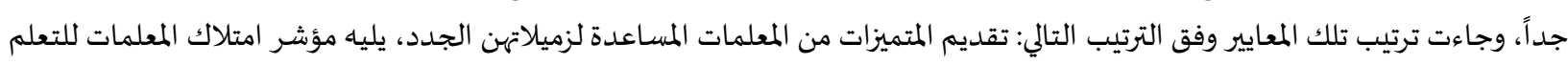
الذاتي، وفي التربيب الأخير تعزيز مفهوم التنمية المهنية للمعلمات.

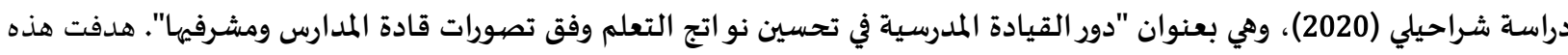

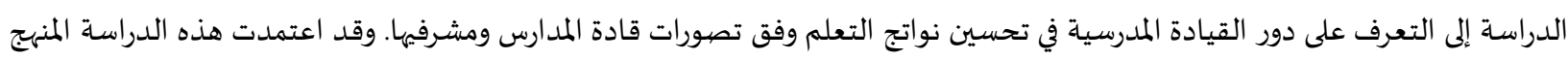

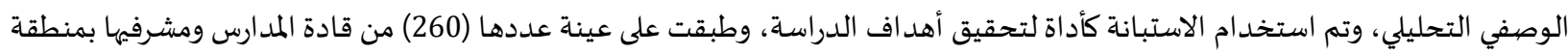

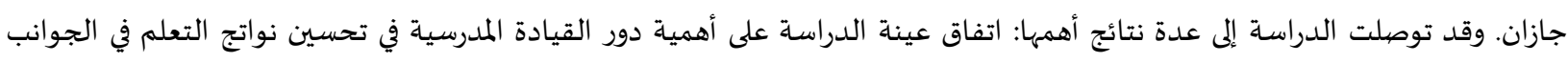

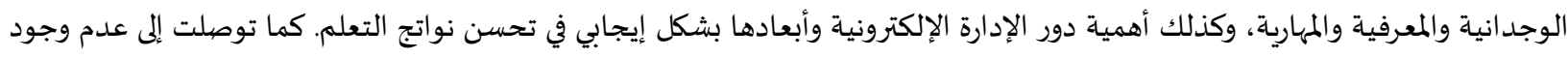

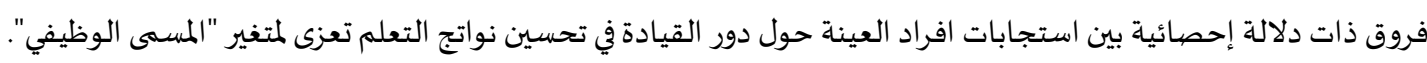

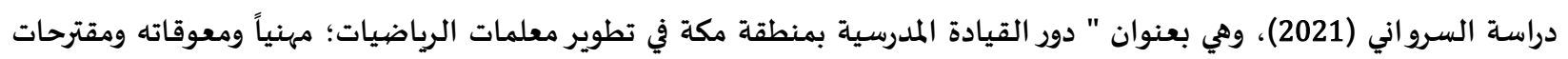

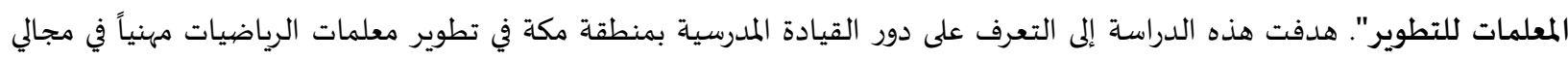

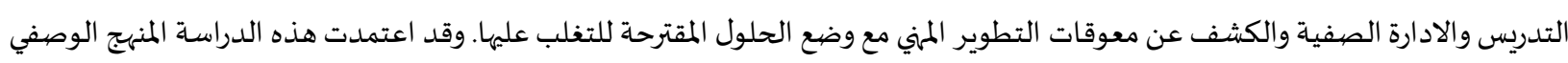

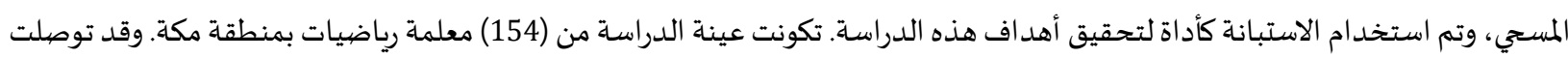

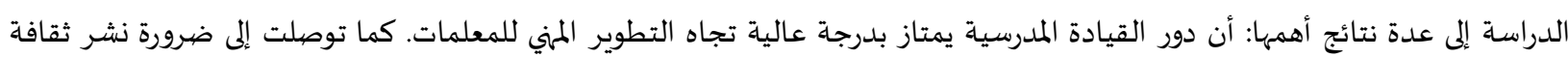

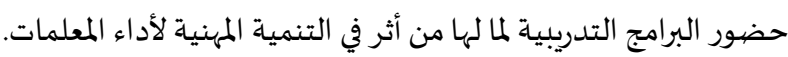


ثانياً: دراسات مرتبطة بتنمية الموارد البشرية:

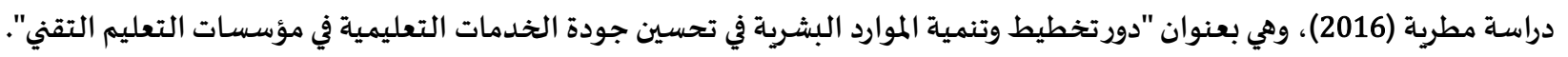

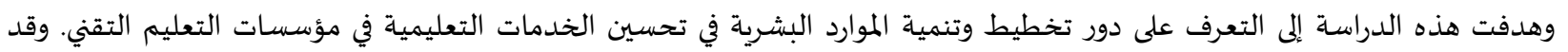

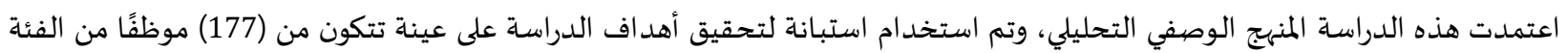

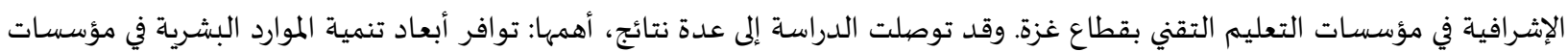

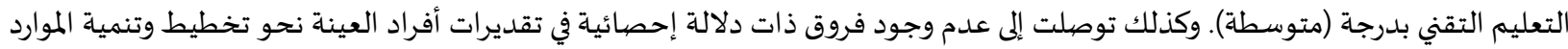

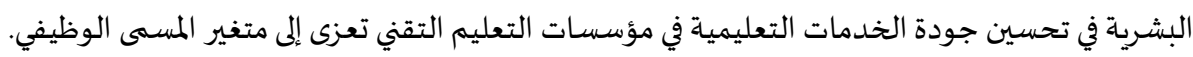
دراسة الخيري (2018)، وهي بعنوان "تنمية الموارد البشرية ودورها في إعداد قيادات المستقبل من وجهة نظر العادية المادلين بإمارة الباحة".

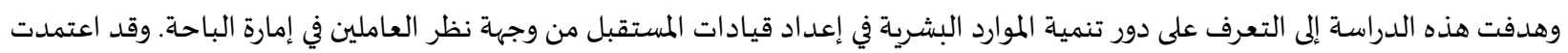

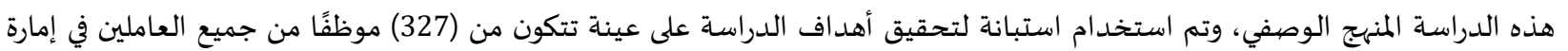

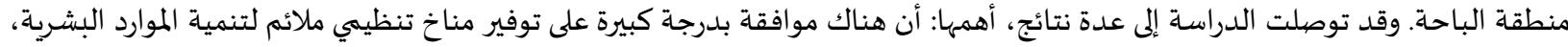

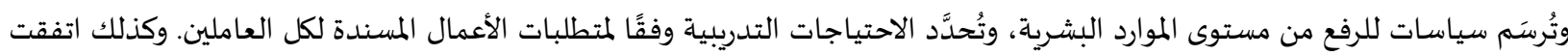
العينة على ضعف الاهتمام بتخطيط المسار الوظيفي للقيادات الشابة، والتركيز على الأعمال التقليدية الروتينية.

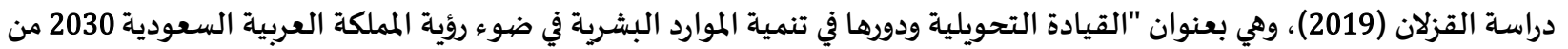

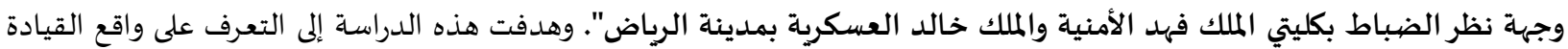

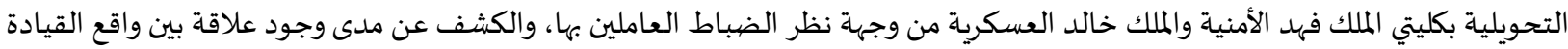

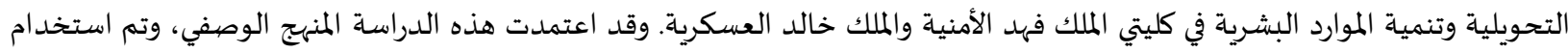

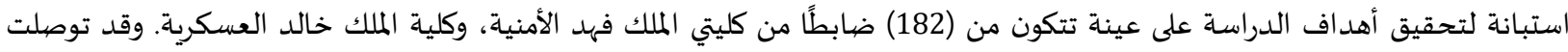

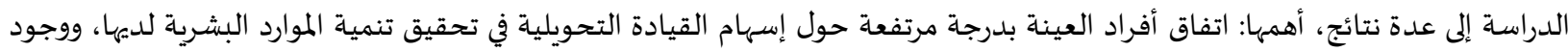
فروق ذات دلالة إحصائية باختلاف المؤهل العلمي لصالح البكالوريوس. دراسة كرتات (2019)، وهي بعنوان "أسباب وعلاج عدم الاستغلال الأمثل للموارد البشرية دراسة تطبيقية على كليات البنات بجامعادة الملك الماتك

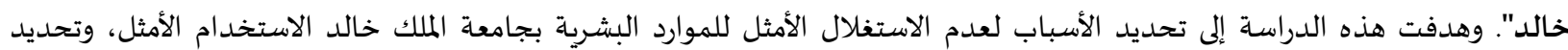

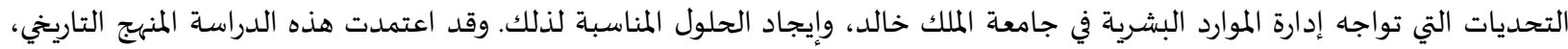

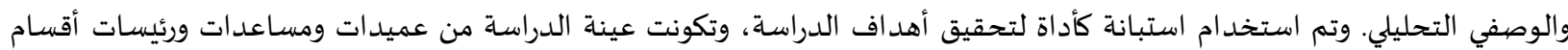

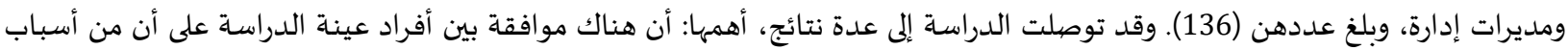

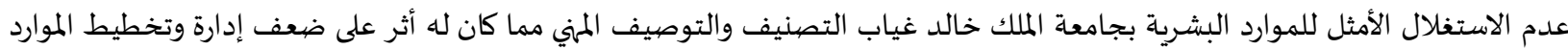
البشرية، الإهمال والتقصير في وضع برامج تأهيلية وتدريبية فعالة ومستمرة.

التعليق على الدراسات السابقة:

من خلال عرض وتحليل العديد من الدراسات السابقة ذات العلاقة بموضوع الدراسة الحالية، فيما يخص الموارد البشرية بصفة عامة، والقيادة الديادة

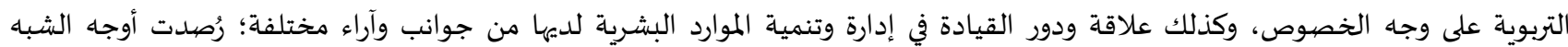

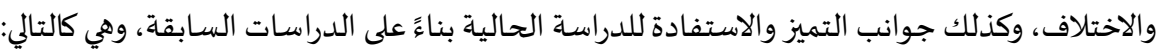
من حيث موضوع الدراسة، تبين للباحثة أهمية القيادة في توظيف القواعد والمبادئ والنظريات الحديثة لبناء إطار تنظيهي داخلي يسهم بفاعلية في إدارة البيئة التربوية بجميع عناصرها، وذلك بعدد من الدراسات السابقة تختص بالقيادة التربوية، وهي دراسة إقبال (Iqbal, 2012)، جولي

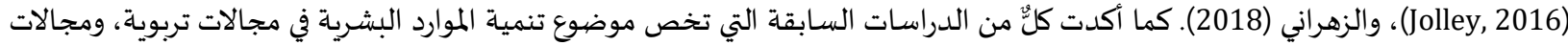

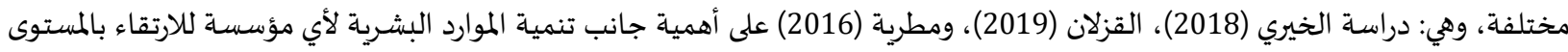
التنظيمي وتحقيق الجودة الشاملة. ركزت العديد من الدراسات السابقة في المجال التربوي على موضوع القيادة وعلاقاقتها بإدارة وتنمية الموارد

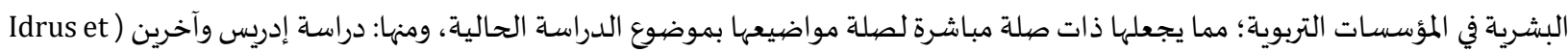

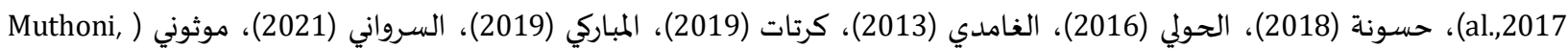

2015)، وميتارو (Mitaru, 2015).

من حيث الأهداف، اختلفت الدراسة الحالية مع الدراسات السابقة، ما عدا دراسة الغامدي (2013)، التي هدفت إلى التعرف على درجة جودة

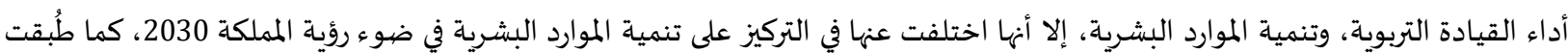


دراسة الغامدي (2013) على عينة تتكون من مديري المدارس الثانوية والمتوسطة (بنين) بالمدينة المنورة، بينما الدراسة الحالية تم تطبيقها على

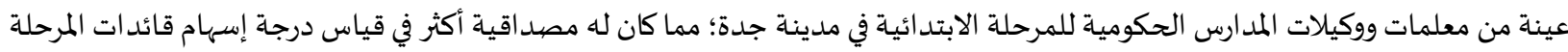
الابتدائية بالمدارس الحكومية بمدينة جدة في تنمية مواردها البشرية.

من حيث المنهج المستخدم للدراسـة، اتفقت الدراسة الحالية مع معظم الدراسات السابقة في اعتمادها المنهج الوصفي، ومنها: دراسة إقبال

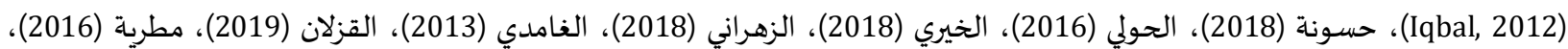

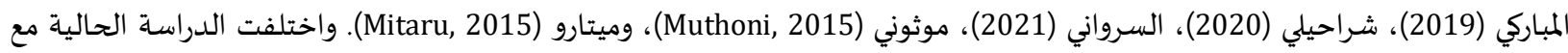

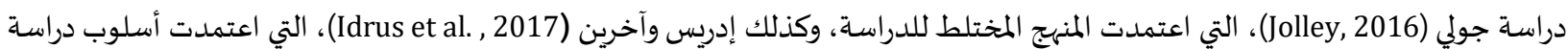
الحالة كمنهج للدراسة. وأيضًا اختلفت هذه الدراسـة مع دراسـة كرتات (2019)، التي اعتمدت المنهج التاريخي، إلى جانب المنهج الوصفي. من حيث الأداة المستخدمة لتحقيق أهداف الدراسـة، اتفقت الدراسة الحالية مع معظم الدراسات السابقة في استخدام الاستبانة كأداة

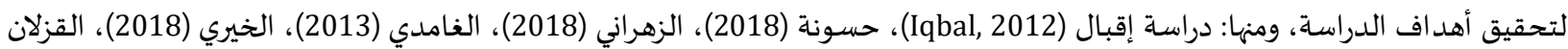
(2019)، كرتات (2019)، مطرية (2016)، المباركي (2019)، شراحيلي (2020)، السرواني (2021)، موثوني (Muthoni, 2015)، وميتارو

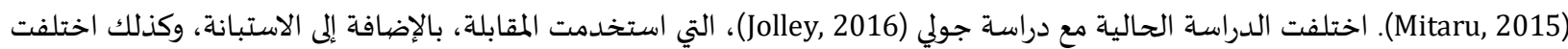
هذه الدراسة مع دراسة إدريس وآخرين (Idrus et al. , 2017)، التي استخدمت أسلوب المقابلة لجمع البيانات، وكذلك اختلفت مع دراسـة الحولي (2016) التي استخدمت المقابلة بالإضافة إلى الاستبانة. من حيث مجتمع وعينة الدراسـة، اختلفت الدراسة الحالية مع جميع الدراسات السابقة؛ حيث طُبقت بعض الدراسـات السابقة على موظفين

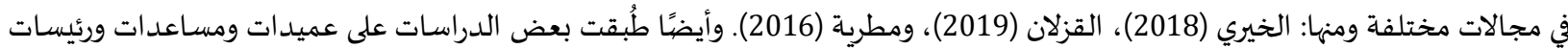

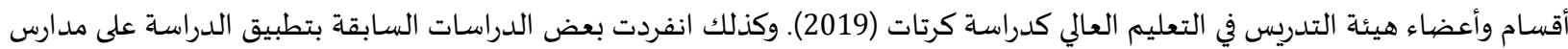

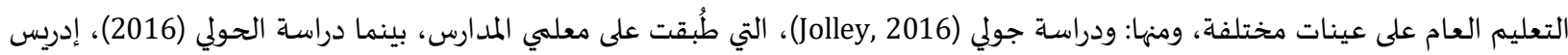

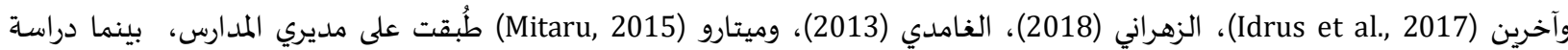

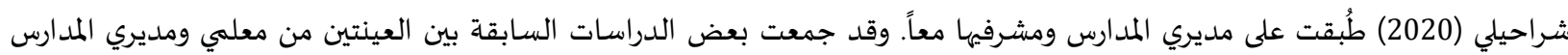

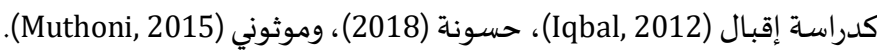
تميزت الدراسة الحالية عن الدراسات السابقة بالنقاط التالية:

تميزت الدراسة الحالية عن جميع الدراسات السابقة بتطبيق الدراسة على عينة من الهيئة التعليمية والإدارية. وقد تم حصرها في معلمات، ووكيلات المدارس، حيث إنهن أقرب عينة للقائدات التربويات، ومن خلالهن يمكن الحصول على صورة واقعية وصادقة فيما يخص موضوع هذه هذه

الدراسة.

يعد موضوع الدراسة الحالية من الدراسـات التربوية النادرة في المملكة العربية السعودية في مجال تنمية الموارد البشرية بالتعليم العام، حيث إن

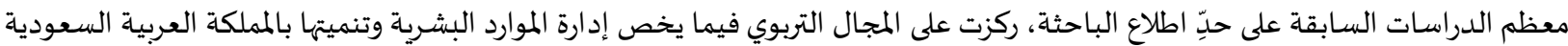
على التعليم العالي. تميزت الدراسة الحالية عن الدراسـات السابقة بتسليط الضوء على درجة إسهام قائدات المرحلة الابتدائية بالمدارس الحكومية بمدينة جدة في تنمية مواردها البشرية وذلك في ضوء رؤية المملكة 2030، في ظل ندرة الدراسات في هذا المجال على حد علم الباحثة. استفادت الدراسة الحالية من الدراسـات السابقة في النقاط التالية: اختيار المنهج المناسب لهذه الدراسة، وهو "المنهج الوصفي"، وكذلك تحديد الأساليب والمعالجات الإحصائية المناسبة والمتبعة في الدراسات المشابهة لهذه الدراسـة. بناء أداة الدراسة الحالية وتطويرها بما يحقق الأهد اف التي وضعت لها وهي "استبانة جمع بيانات". إثراء الإطار النظري لهذه الدراسة. الاستفادة من الكتب والمراجع والدراسات ذات الصلة التي تم الإشارة إليها في الدراسات السابقة؛ مما كان له أثر إيجابي في توفير الوقت والجهد على الباحثة بالرجوع إلى المصادر المذكورة مسبقًا في تلك الدراسات. 
3. منهجية الدراسـة وإجراءاتها

1.3. منهج الدراسة:

تم استخدام المنهج الكمي الوصفي المستي؛ لأنه المنهج المناسب لطبيعة هذه الدراسة، ولتحقيق أهدافها في التعرف على درجة إسهام قائدات المرحلة الابتدائية بالمدارس الحكومية بمدينة جدة في تنمية مواردها البشرية في ضوء رؤية المملكة 2030؛ حيث إنها يعتمد على جمع المعلومات والبيانات

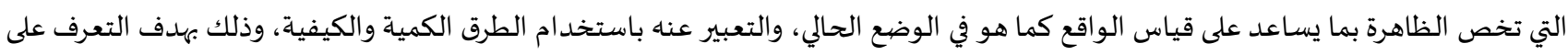
جوانب القوة والضعف لقياس مدى صلاحية هذا الوضيع، أو مدى الحاجة لإحداث تغيرات جزئية أو كلية فيه. (عبيدات وآخرين، 2016)

2.3 مجتمع الدراسة:

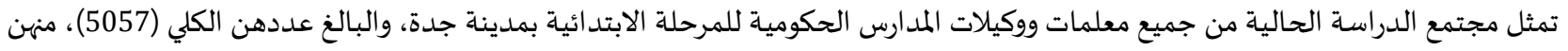

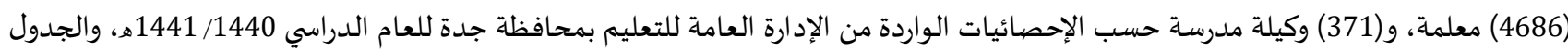

\begin{tabular}{|c|c|c|c|}
\hline النسبة من المجتمع الكلي & العدد & المسسى الوظيفي & م \\
\hline$\% 92$ & 4686 & معلمة & 1 \\
\hline$\% 8$ & 371 & وكيلة مدرسة & 2 \\
\hline$\% 100$ & 5057 & المجمموع & \\
\hline
\end{tabular}
التالي يوضح ذلك:

3.3 عينة الدراسـة: تكونت عينة الدراسـة من (383) معلمة ووكيلة مدرسة حكومية للمرحلة الابتدائية بمدينة جدة، وقد وقع اختيارهن بالطريقة العشوائية البسيطة؛ حيث تمثل عينة الدراسة ما نسبتـه (14.68\%) من مجتمع الدراسة الكلي المتمثل في جميع معلمات ووكيلات المدارس الحكومية للمرحلة الابتد ائية بمدينة

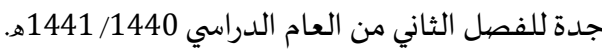
4.3 خصبائص عينة الدراسة:

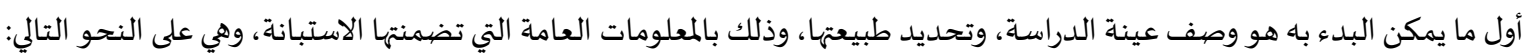
توزيع أفراد عينة الدراسـة وفق متغير المسسى الوظيفي. تم حساب التكرارات والنسب المئوية لأفراد عينة الدراسـة وفقًا للمسـى الوظيفي كما تبينها النتائج بالجدول التالي: جدول (2): توزيع أفراد عينة الدراسة وفقًا لمتغير المسسى الوظيفي

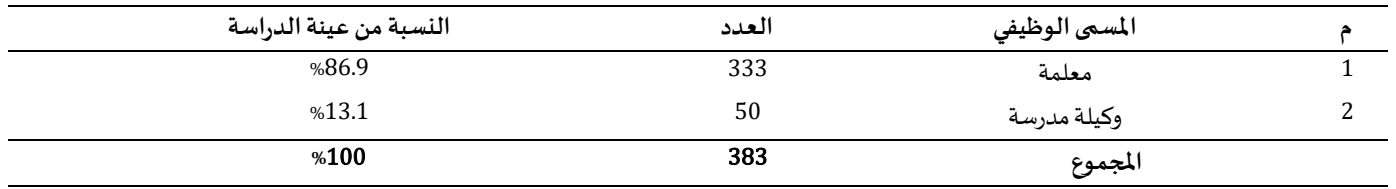

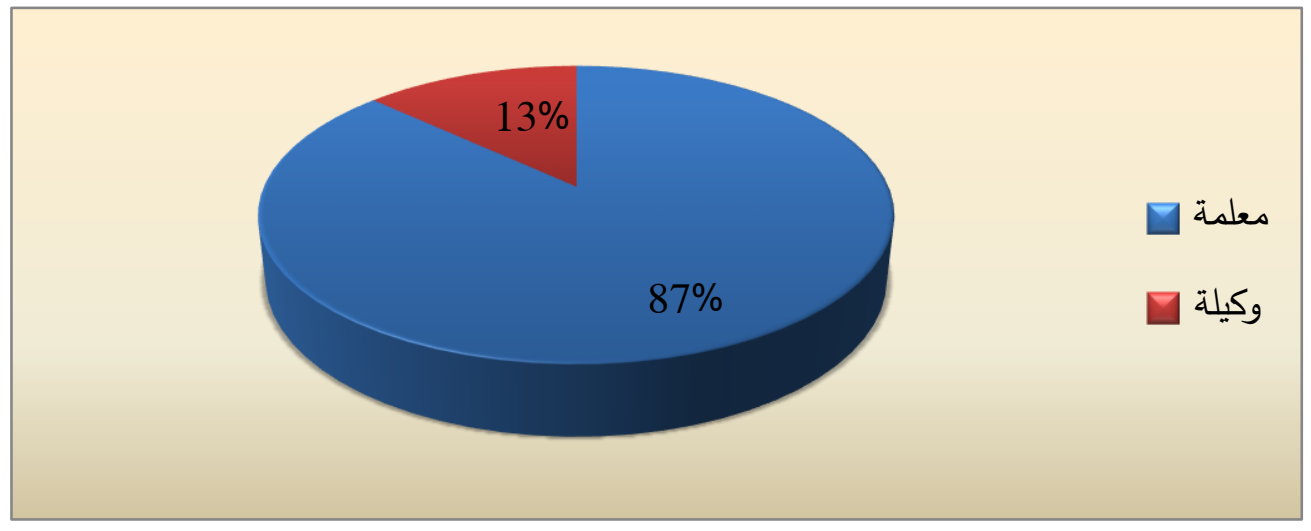

$$
\text { شكل (1): توزيع عينة الدراسة حسب متغير المسمى الوظيفي }
$$

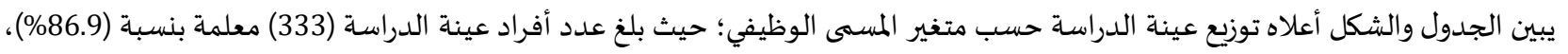

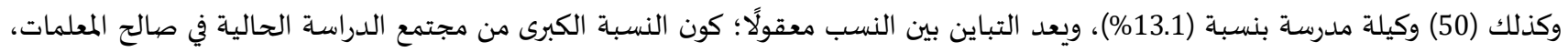


مقارنةً بعدد الوكيلات؛ ويعزى ذلك إلى وجود عدد وكيلة واحدة إلى عدد ثلاث وكيلات كحد أقصى في المدرسة الواحدة، وذلك يعتمد على عدد طالبات كل مدرسة.

5.3. أداة الدِّراسَـة: استخدمت الباحثة الاستبانة كأداة أساسية لجمع المعلومات المطلوبة، ودعم جوانب الدراسة النظرية بالجوانب التطبيقية، من خلال الإجابة عن

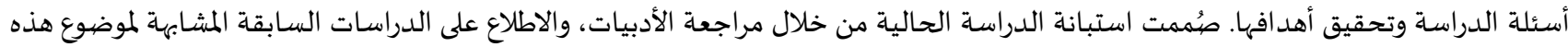

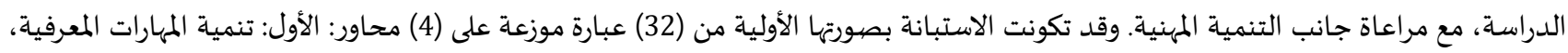

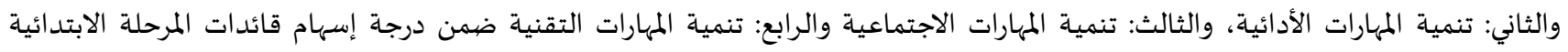

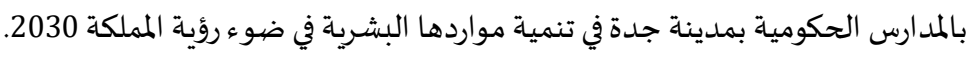

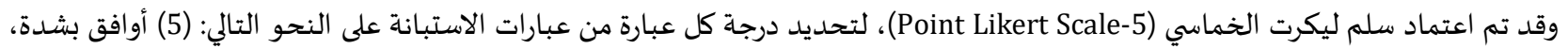

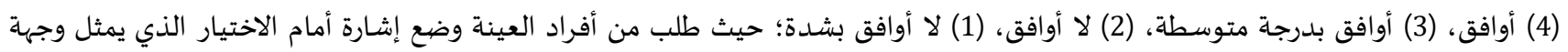

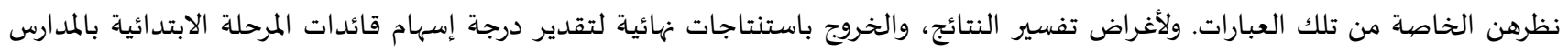
الحكومية بمدينة جدة في تنمية مواردها البشرية، في ضوء رؤية المملكة 2030، فقد تم اعتماد الاتجاه التالي لمقياس سلم ليكرت الخماسي، والجدول التالي يوضح ذلك:

جدول (3): المتوسط المرجح لمقياس سلم ليكرت الخماسي

\begin{tabular}{|c|c|}
\hline درجة المو افقة & المتوسط المرجح \\
\hline مرتفعة جدًًا & من 4.20 إلى 5,00 \\
\hline مرتفعة & من 3.40 إلى 4.19 \\
\hline متوسطة & من 2.60 إلى 3.39 \\
\hline منخفضة & من 1.80 إلى 2.59 \\
\hline منخفضية جدًا & من 1 إلى 1.79 \\
\hline
\end{tabular}

6.3. صهدق أداة الدراسـة:

التأكد من صيدق أداة الدراسـة يعد من الخطوات الهامة في كل مقياس يُصهمَّم، وعلى ذلك اعتمدت الباحثة على طريقتين للتأكد من صهدق أداة الدراسـة، هما:

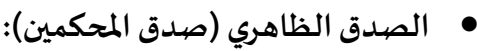

عُرضت الاستبانة بصورتها الأولية على مجموعة من المُحكِّمين المتمثلين في عدد من المختصين والخبراء من أعضاء هيئة التدريس بالجامعات

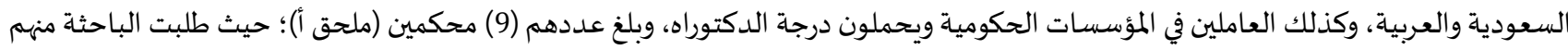
الاطلاع على الأداة لإبداء الملاحظات والآراء عن مدى ملاءمة هذه العبارات ومناسبتها لموضوع الدراسة،، وارتباطها بالمحور الذي تنتمي إلياء، وسلامة

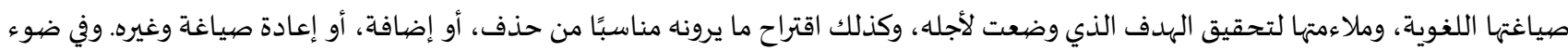

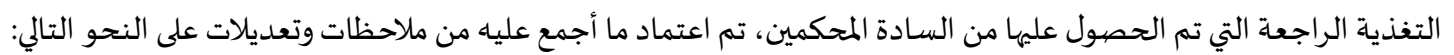
1. تم إعادة صياغة بعض فقرات الاستبانة بصياغة لغوية معدلة طبقاً للاقتراحات.

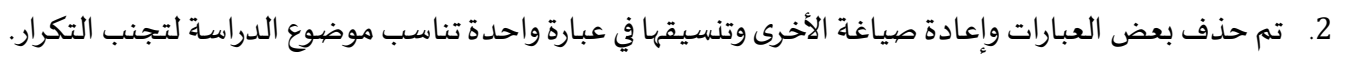
3. نقل بعض الفقرات إلى المحاور المناسبة لها.

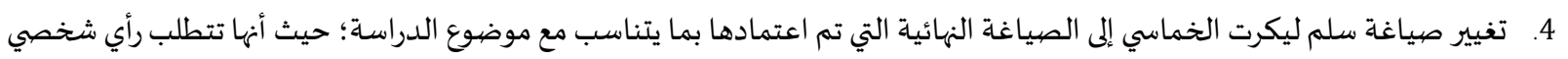
5. للمستجيب تجاه موضوع معين. وانطلاقًا من تلك الإجراءات فقد تم التوصل إدهاه موضوع معند (33) فقرة تندرج تحت أربع محاور أساسية وهي: تنمية المهارات المعرفية- تنمية المهارات الأدائيةتنمية المهارات الاجتماعية- تنمية المهارات التقنية. • • • صدامت الاتساق الداخلي:

قامت الباحثة بالتأكد من صدق الاتساق الاتساق الداخلي من خلال حساب معامل الارتباط (بيرسون) بين درجة كل عبارة من عبارات محاور الدراسة

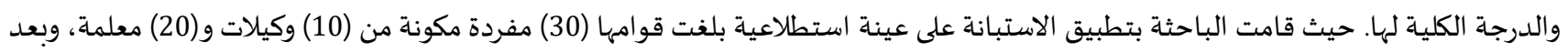
التطبيق قامت الباحثة بحساب معامل الارتباط بين كل فقرة والدرجة الكلية للمحور الذي تنتمي إليه كما هو موضح في فئية الجداول التالية: 
جدول (4): معاملات ارتباط الاتساق الداخلي بين الفقرة والدرجة الكلية ومعامل الثبات لمحورتنمية المهارات المعرفية

\begin{tabular}{|c|c|c|}
\hline معامل الارتباط (ييرسون) & 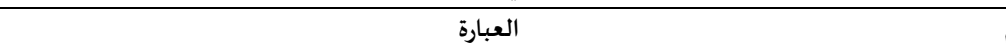 & م \\
\hline $0.60^{* *}$ & تحث القائدة مواردها البشرية على توظيف منهج البحث العلمي في أداء الأعمال المختلفة. & 1 \\
\hline${ }^{*} 0.83$ & تزود القائدة الموارد البشرية بالمعارف المتجددة عن طبيعة أعمالهن، وأساليب أدائها بشكل أفضل. & 2 \\
\hline **0.82 & تشجحع القائدة مواردها البشرية على استخدام آليات حديثة في التفكير المنظم من خلال حلقات البحث، وورش & 3 \\
\hline$* 0.42$ & تسمح القائدة لمواردها البشرية بتبادل المعارف والخبرات. & 4 \\
\hline${ }^{*} 0.83$ & تقوم القائدة بإثراء معلومات مواردها البشرية من خلال تزويدهن بالمصادر العلمية المختلفة. & 5 \\
\hline$* 0.58$ & تشجع القائدة روح الإبداع والابتكار في أساليب العمل لدى مواردها البشرية. & 6 \\
\hline & * مستوى الارتباط دال إحصائيًا عند مستوى (0.01) & \\
\hline
\end{tabular}

يتبين من الجدول أعلاه أن جميع معاملات الارتباط بين العبارات المككونة للمحور وبين المجموع الكلي للمحور نفسه دالة إحصائيًّ عند مستوى المائي

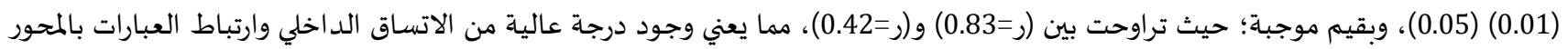

الذي تنتهي إليه، وهذا يدل على درجة الصددق البنائي العالية لمقياس محور تنمية المهارات المعرفية.

\begin{tabular}{|c|c|c|}
\hline معامل الارتباط (بيرسون) إن & 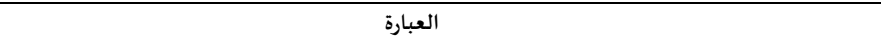 & $p$ \\
\hline$* 0.42$ & توزع القائدة المهام على مواردها البشرية وفق المؤهل، والتخصص العلمي، والخبرات المعرفية، والقدرات المهارية. & 1 \\
\hline$* * 0.82$ & توفر القائدة مناخًا إيجابيًا يساعد على إثارة الدافعية، ورفع مستويات الأداء. & 2 \\
\hline$* * 0.86$ & تخطط القائدة لبرامج التطوير الممني لمواردها البشرية في المدرسة بالاستناد إلى معطيات التقويم الدوري. & 3 \\
\hline$* 0.58$ & تتخذ القائدة قرارات متوازنة بإشراك المشرفات والوكيلات في عملية التخطيط لتنمية مواردها البشرية. & 4 \\
\hline$* * 0.82$ & تتابع القائدة أداء مواردها البشرية لرصد جوانب القوة لتعزيزها، وجوانب الضعف للتغلب علهها. & 5 \\
\hline$* 0.92$ & تشجع القائدة مواردها البشرية على التقييم الذاتي للأداء، بما فهيا عمليات التغذية الراجعة الداعمة للتحسين منه. & 6 \\
\hline$* 0.85$ & تحدد القائدة الاحتياجات التدرببية لمواردها البشرية بأساليب علمية دقيقة وفق متطلبات رؤية المملكة 2030. & 7 \\
\hline$* 0.79$ & تستعين القائدة بخبراء مختصيين في المجال التربوي والإداري لتنمية مواردها البشرية، وتحقيق الشراكة المجتمعية. & 8 \\
\hline$* 0.78$ & تتواصل القائدة مع الجهات المعنية في إدارة التعليم للاستفادة من أشكال ونظم التدربب والتطوير المحلي والدولي. & 9 \\
\hline$* * 0.86$ & تعزز القائدة مهارات تحمل المسئولية، واتخاذ القرار، وحل المشكلات لدى مواردها البشرية في المدرسة. & 10 \\
\hline$* 0.51$ & تفوض القائدة بعض الصلاحيات لمواردها البشرية لإنجاز العمل. & 11 \\
\hline${ }^{* *} 0.71$ & تتيح القائدة فرصة المشاركة الحقيقية لمواردها البشرية في تحديد الأطر العامة للخطط التنموية داخل المدرسة. & 12 \\
\hline$* * 0.87$ & تهتم القائدة بتنمية المهارات القيادية لدى مواردها البشرية. & 13 \\
\hline$* 0.78$ & تحرص القائدة على عقد ورش عمل لتنمية مهارات مواردها البشرية في التخطيط والتقويم. & 14 \\
\hline \multicolumn{3}{|c|}{ ** * مستوى الارتباط دال إحصائيًا عند مستوى (0.01) } \\
\hline
\end{tabular}

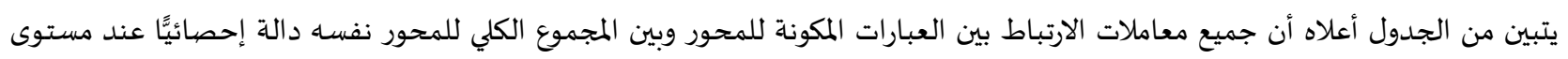

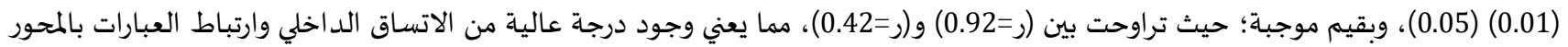

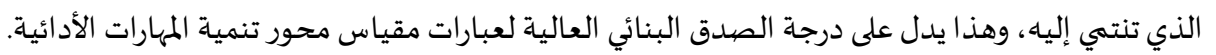
جدول (6): معاملات ارتباط الاتساق الداخلي بين الفقرة والدرجة الكلية ومعامل الثبات لمحورتنمية المهارات الاجتماعية

\begin{tabular}{|c|c|c|}
\hline معامل الارتباط (ييرسون) & العبارة & م \\
\hline$* 0.84$ & تعزز القائدة بناء علاقات داعمة وإيجابية بين جميع مواردها البشرية في المدرسة. & 1 \\
\hline$* 0.86$ & تحرص القائدة على التفاعل الاجتماعي مع مواردها البشرية من خلال (الثقة، والالتزام المتبادل، والاتصال الفعال). & 2 \\
\hline$* 0.86$ & تعزز القائدة الإحساس بالذات وإعلاء قيمة العنصر البشري داخل المجتمع المدرسي. & 3 \\
\hline$* 0.84$ & ترتب القائدة برنامجًا للزيارات التبادلية للخبرات بين مواردها البشرية لزيادة الروابط الاجتماعية. & 4 \\
\hline$* 0.84$ & تدفع القائدة مواردها البشرية لبناء فريق عمل للتعلم والمشاركة في التخطيط الاستراتيجي للمدرسة. & 5 \\
\hline$* 0.86$ & تعتمد القائدة مبدأ المنظمات التعليمية التشاركية في وضع خطط تنمية الموارد البشرية في المدرسة. & 6 \\
\hline$* 0.80$ & ت توظف القائدة النظام التشاوري في العمل. & 7 \\
\hline
\end{tabular}

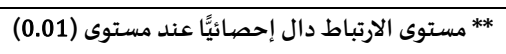


يتبين من الجدول أعلاه أن جميع معاملات الارتباط بين العبارات المكونة للمحور وبين المجموع الكلي للمحور نفسـه دالة إحصيائيًا عند مستوى

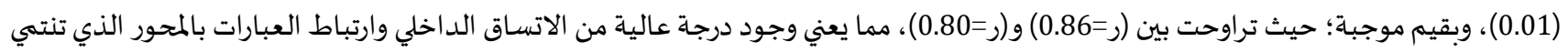

إلياه، وهذا يدل على درجة الصدق البنائي العالية لمقياس محور تنمياة المهارات الاجتماعية.

\begin{tabular}{|c|c|c|}
\hline 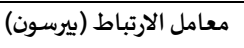 & 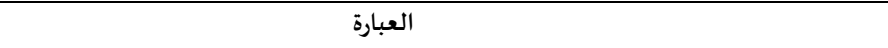 & s \\
\hline$* * 0.88$ & تحرص القائدة على تهيئة بيئة تقنية حديثة من خلال روية مستقبلية تعزز رؤية 2030 والتحول الوطني. & 1 \\
\hline$* 0.87$ & توجه القائدة مواردها البشرية إلى التعلم والتدربب الاحترافي في المجال الرقهي. & 2 \\
\hline$* 0.77$ & تحث القائدة مواردها البشرية على توظيف الأدوات والبرامج والتقنية الحديثة في أداء الأعمال المختلفة. & 3 \\
\hline$* 0.90$ & تشجع القائدة مواردها البشرية على الاستفادة من المواقع والمصادر الرقمية في التعلم والتطوير الذاتي. & 4 \\
\hline$* 0.91$ & تستثمر القائدة أنظمة التعلم والتقنية الحديثة في استمرارية التنمية والتطوير. & 5 \\
\hline$* * 0.89$ & تشجع القائدة مواردها البشرية على التقنية الحديثة في التعاملات والاجتماعات الرسمية. & 6 \\
\hline
\end{tabular}

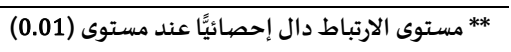

يتبين من الجدول أعلاه أن جميع معاملات الارتباط بين العبارات المكونة للمحور وبين المجموع الكلي للمحور نفسه دالة إحصيائيًا عند مستوى

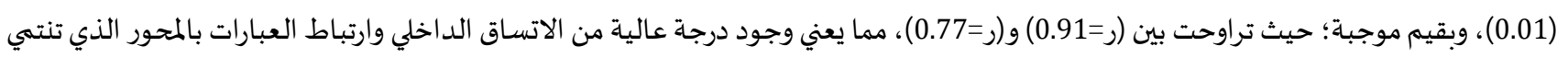
إليه، وهذا يدل على درجة الصدق البنائي العالية لمقياس محور تنمية المهارات التقنية.

7.3 ثبات أداة الدراسـة:

تم التحقق من ثبات أداة الدراسة باستخدام معادلة ألفا كرونباخ (Cronbach's Alpha Coefficient)، ويوضح الجدول التالي معاملات الثبات

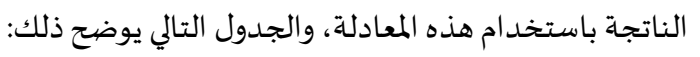

جدول (8): معاملات ثبات ألفا كرونباخ طبقًا لمحاور الاستبانة

\begin{tabular}{|c|c|}
\hline معامل ألفا كرونباخ & المحور \\
\hline 0.88 & تنمية المهارات المعرفية \\
\hline 0.95 & تنمية المهارات الأدائية \\
\hline 0.95 & تنمية المهارات الاجتماعية \\
\hline 0.96 & تنمية المهارات التقنية \\
\hline 0.97 & الثبات الكلي للمقياس \\
\hline
\end{tabular}

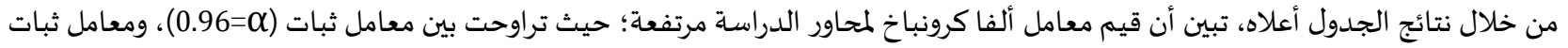

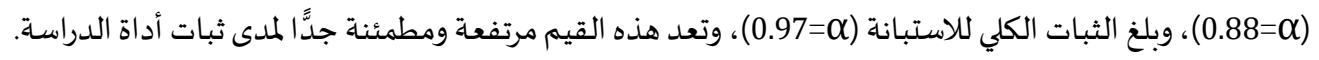

8.3 الأساليب الإحصيائية:

بناء على طبيعة الدراسـة الحالية، وأهدافها، حُللت البيانات باستخدام برنامج الحزم الإحصائية للعلوم الاجتماعية (SPSS)، واستخراج النتائج وفقًا للأساليب الإحصائية التالية:

ه معامل ارتباط بيرسون (Pearson Correlation Coefficient) للتحقق من الصدق البنائي باستخدام أسلوب الاتساق الداخلي لمحاور الدراسـة. معامل ألفا كرونباخ (Cronbach's Alpha Coefficient) لتقدير ثبات عبارات الاستبانة ككل.

التحليل الوصفي (Descriptive Analysis) وعن طريقه تم احتساب التكرارات والنسب المئوية للتعرف على خصائص الأفراد من عينة البحث وفقًا للبيانات الأولية، وكذلك المتوسطات الحسابية والانحرافات المعيارية لحساب متوسطات العبارات، والدرجات الكلية والفرعية لمحاور

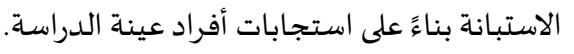

اختبار ت لعينتين مستقلتين (Independent-Samples T Test) لمعرفة إن كانت هناك فروق ذات دلالة إحصائية عند درجة معنوية أقل (0.05) بين اتجاهات مفردات العينة نحو محاور الاستبانة، تعود إلى متغير المسسى الوظيفي.

4. نتائج الدراسـة وتفسيرها ومناقشتها للإجابة عن السؤال الرئيس: ما درجـة إسهام قائدات المرحلة الابتدائية بالمدارس الحكومية بمدينة جـدة في تنمية مواردها البشـرية، في ضيوء رؤية

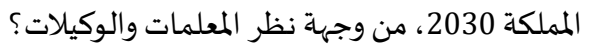


تم حساب المتوسطات الحسابية والانحرافات المعيارية لكل عبارة مرتبطة بمحورها والمحور بشكل عام؛ حيث كانت على النحو التالي: 1.4. النتائج المتعلقة بالسؤال الأول: ما درجة إسهام قائدات المرحلة الابتدائية بالمدارس الحكومية بمدينة جدة في تنمية (المهارات المعرفية) لدى

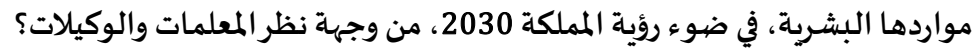

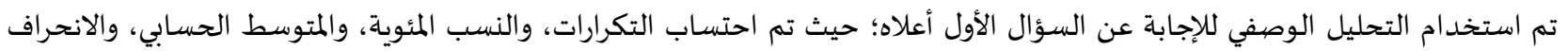

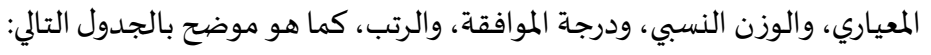
جدول (9): المتوسطات الحسابية والانحر افات المعيارية والترتيب لاستجابات أفراد العينة لعبارات المحور الأول "تنمية المهارات المعرفية" مرتبة تنازليًا حسب متوسطات

\begin{tabular}{|c|c|c|c|c|c|c|}
\hline \multicolumn{7}{|c|}{ المو افقة } \\
\hline الرتب & درجة & 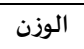 & الانحراف & المتوسط & 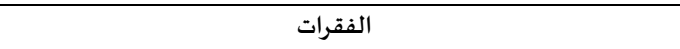 & رقم \\
\hline & المو افقة & النسبي & المعياري & الحسابي & & 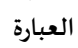 \\
\hline 1 & مرتفًّا & $\% 84.4$ & 0.81 & 4.22 & تسمح القائدة لمواردها البشرية بتبادل المعارف والخبرات. & 4 \\
\hline 2 & مرتفعة & $\% 83.6$ & 0.84 & 4.18 & تشجح القائدة روح الإبداع والابتكار في أساليب العمل لدى مواردها البشرية. & 6 \\
\hline 3 & مرتفعة & $\% 80.2$ & 0.95 & 4.01 & 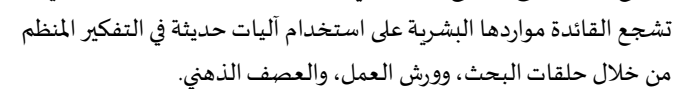 & 3 \\
\hline 4 & مرتفعة & $\% 79$ & 1.00 & 3.95 & تزائها بشكل أفضائدة الموارد البشرية بالمعارف المتجددة عن طبيعة أعمالهن، وأساليب & 2 \\
\hline 5 & مرتفعة & $\% 75.6$ & 1.06 & 3.78 & تقوم القائدة بإثراء معلومات مواردها البشرية من خلال تزويدهن بالمصادر & 5 \\
\hline 6 & مرتفعة & $\% 74.6$ & 1.06 & 3.73 & تحخث القائدة مواردها البشرية على توظيف منهج البحث العلمي في أداء الأعمال & 1 \\
\hline & مرتفعة & \%77.8 & 0.80 & 3.98 & المحتور الأول ككل & \\
\hline
\end{tabular}

ويتضح من الجدول أعلاه أن عبارات المحور انحصرت انحصارًا كبيرًا في درجة موافقة (مرتفعة)، حيث بلغت الدرجة الكلية لمتوسط المحور (3.98)،

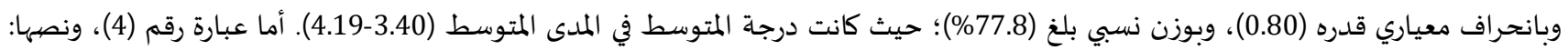

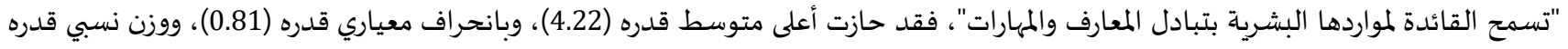

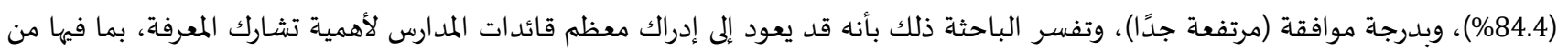
تبادل للأفكار الإبداعية والخبرات والتجارب المختلفة، ومن ثم تحقيق الجودة في العمل. وبذلك تتفق نتائج هذه الدراسة مع نتائج دراسة حسونة

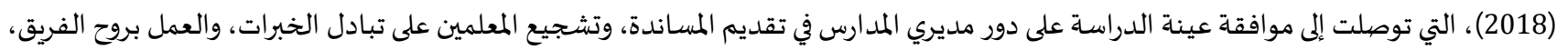
وكذلك تتفق نتائج الدراسة الحالية مع نتائج دراسة الزهراني (2018)، التي توصلت إلى أهمية التشارك المعرفي، واستخدام أسلوب التفكير الجماعي والحوار بما يطور الأداء. بينما حازت العبارة رقم (1)، ونصها: "تحث القائدة مواردها البشرية على توظيف منهج البحث العلمي في أداء الأعمال المختلفة" أقل متوسط قدره

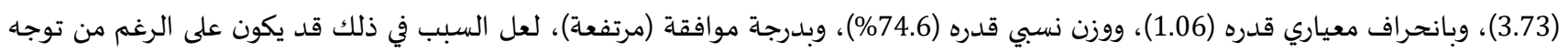

غالبية القائدات إلى الطرق المنهجية المنظمة في العمل، إلا أن هناك بعض من القائدات اللاتي يتمسكن بالطرق الترون التقليدية الروتينية في إنجاز العمل. 2.4. النتائج المتعلقة بالسؤال الثاني: ما درجة إسهام قائدات المرحلة الابتدائية بالمدارس الحكومية بمدينة جدة في تنمية (المهارات الأدائية) لدى

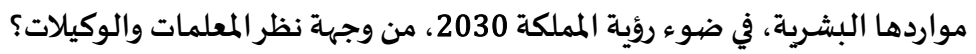

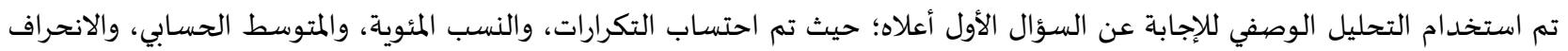

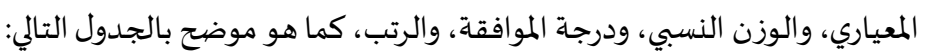
جدول (10): المتوسطات الحسابية والانحر افات المعيارية والترتيب لاستجابات أفراد العينة لعبارات المحور الثاني "تنمية المهارات الأدائية" مرتبة تنازليًا حسب متوسطات المو افقة

\begin{tabular}{|c|c|c|c|c|c|c|}
\hline الرتب & 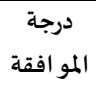 & 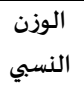 & المعياري & الحسابي & 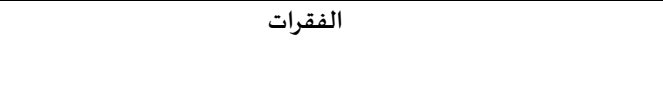 & 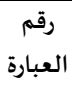 \\
\hline 1 & 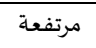 & $\% 79.6$ & 0.88 & 3.98 & تفوض القائدة بعض الصلاحيات لمواردها البشرية لإنجاز العمل. & 11 \\
\hline 2 & مرتفعة & $\% 79.4$ & 0.89 & 3.97 & تعزاردا القيائدة مهارات تحمل المسئولية، واتخاذ القرار، وحل المشكلات لدى & 10 \\
\hline 3 & 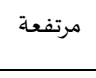 & $\% 79.4$ & 0.89 & 3.97 & توفر القائدة مناخًا إيجابيًً يساعد على إثارة الدافعية، ورفع مستويات الأداء. & 2 \\
\hline
\end{tabular}




\begin{tabular}{|c|c|c|c|c|c|c|}
\hline 4 & مرتفعة & $\% 79.2$ & 0.88 & 3.96 & التابع القائدة أداء مواردها البشرية لرصد جوانب القوة لتعزيزها، وجوانب & 5 \\
\hline 5 & مرتفعة & \%78.6 & 0.91 & 3.93 & تشجع القائدة مواردها البشرية على التقييم الذاتي للأداء، بما فيها عمليات & 6 \\
\hline 6 & 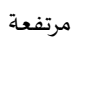 & \%78.4 & 0.90 & 3.92 & توزغ القائدة المهام على مواردها البشرية وفق المؤهل، والتخصص العلمي، & 1 \\
\hline 7 & 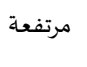 & \%78.2 & 0.94 & 3.91 & تهتم القائدة بتنمية المهارات القيادية لدى مواردها البشرية. . & 13 \\
\hline 8 & مرتفعة & \%77.8 & 0.94 & 3.89 & تلخيح القائدة فرصة المشاركة الحقيقية لمواردها البشرية في تحديد الأطر العامة & 12 \\
\hline 9 & مرتفعة & \%77.7 & 0.99 & 3.89 & تحرص القائدة على عقد ورش عمل لتنمية مهارات مواردها البشرية في التخطيط & 14 \\
\hline 10 & مرتفعة & \%77.4 & 0.96 & 3.87 & تخطط القائدة لبرامج التطوير المهني لمواردها البشرية في المدرسة بالاستناد إلى المئم الدورئ & 3 \\
\hline 11 & 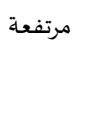 & $\% 77.2$ & 0.98 & 3.86 & تتنخذ القائدة قرارات متوازنة بإشراك المشرفات والوكيلات في عملية التخطيط & 4 \\
\hline & 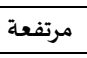 & 77.56 & 0.80 & 3.88 & المحور الثاني ككل & \\
\hline
\end{tabular}

ويتضح من الجدول أعلاه أن عبارات المحور انحصرت انحصارًا كليَّا في درجة موافقة (مرتفعة)؛ حيث بلغت الدرجة الكلية لمتوسط المحور (3.88)،

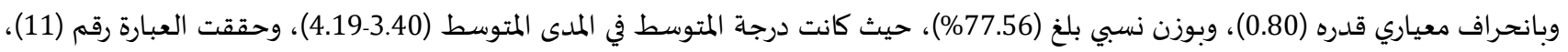
ونصها: "تفوض القائدة بعض الصلاحيات لمواردها البشرية لإنجاز العمل" أعلى متوسط، وقدره (3.98)، وبانحراف معياري قدره (0.88)، ووزن نسبي

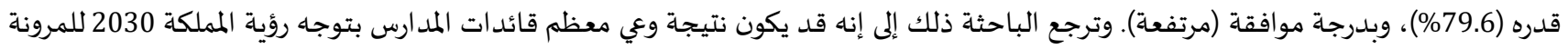

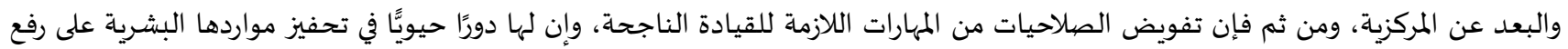

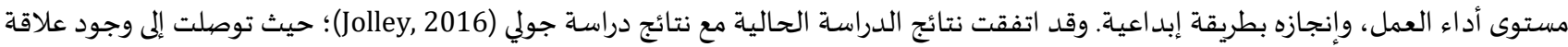

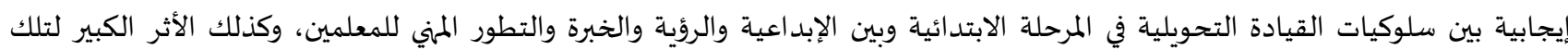

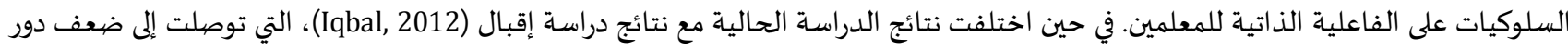

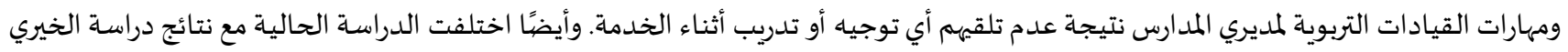
(2018)، التي توصلت إلى ضعف الاهتمام بتخطيط المسار الوظيفي لتنمية المهارات الإبداعية والقيادية للعاملين، والتركيز على إنجاز الأعمال بالطريقة

التقليدية والروتينية. بينما حازت العبارة رقم (8)، ونصها: "تستعين القائدة بخبراء مختصين في المجال التربوي والإداري لتنمية مواردها البشرية، وتحقيق الشراكة

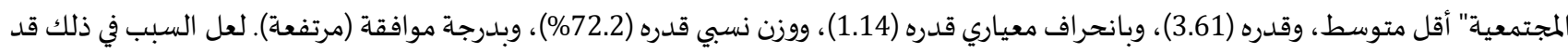

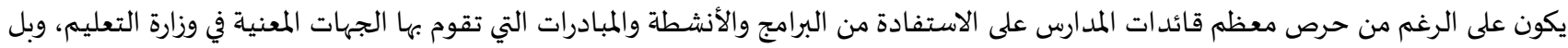

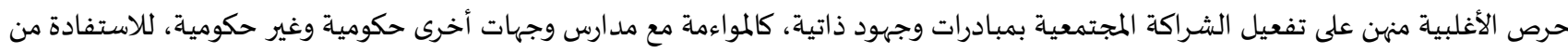

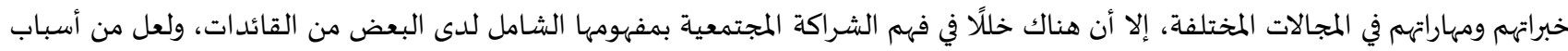

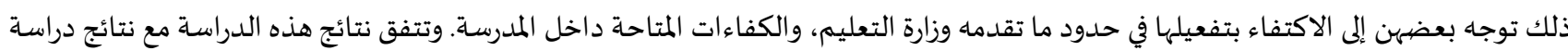

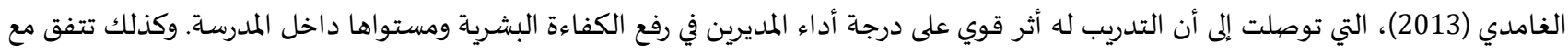

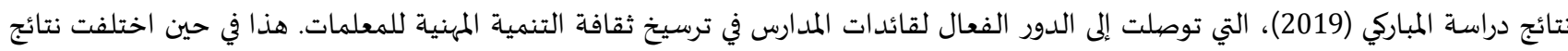
الدراسة الحالية مع نتائج دراسة كرتات (2019)، التي توصلت إلى التقصير والإهمال في وضع برامج تأهيلية وتدريبية فعالة ومستمرة في الجامعة. 3.4. النتائج المتعلقة بالسؤال الثالث: ما درجة إسهام قائدات المرحلة الابتدائية بالمدارس الحكومية بمدينة جدة في تنمية (المهارات الاجتماعية)

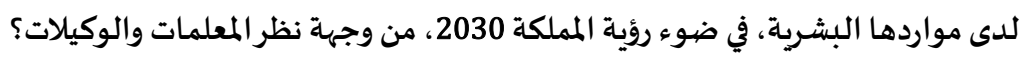

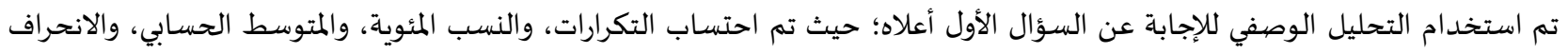

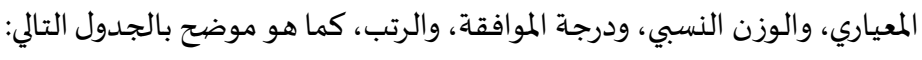


جدول (11): المتوسطات الحسابية والانحر افات المعيارية والترتيب لاستجابات أفراد العينة لعبارات المحور الثالث "تنمية المهارات الاجتماعية" مرتبة تنازيلًا حسب متوسطات

\begin{tabular}{|c|c|c|c|c|c|c|}
\hline \multicolumn{7}{|c|}{ 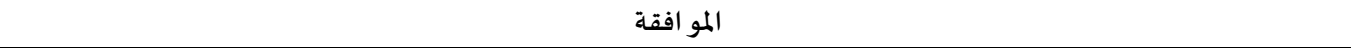 } \\
\hline \multirow[t]{2}{*}{ الرتب } & 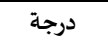 & 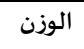 & 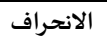 & المتوسط & \multirow[t]{2}{*}{ 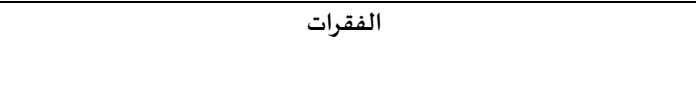 } & 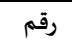 \\
\hline & 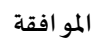 & النسبي & 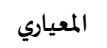 & الحسابي & & لعبارة \\
\hline \multirow[t]{2}{*}{1} & مرتفعة & $\% 82.8$ & 0.86 & 4.14 & تحرص القائدة على التفاعل الاجتماعي مع مواردها الشربة من خلال (الثقة، & 2 \\
\hline & & & & & والالتزام المتبادل، والاتصال الفعال). & \\
\hline \multirow[t]{2}{*}{2} & مرتفعة & $\% 81.6$ & 0.89 & 4.08 & & 1 \\
\hline & & & & & تعزز القائدة بناء علاقات داعمة وإيجابية بين جميع مواردها البشرية في المدرسة. & \\
\hline \multirow[t]{2}{*}{3} & 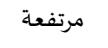 & $\% 81.4$ & 0.89 & 4.07 & الذات واعلاء قيمة العنصر الشرى داخل المجتمع & 3 \\
\hline & & & & & المدرسي. & \\
\hline \multirow[t]{2}{*}{4} & مرتفعة & $\% 78.2$ & 0.96 & 3.91 & t th i & 7 \\
\hline & & & & & توظف القائدة النظام التشاوري في العمل. & \\
\hline \multirow[t]{3}{*}{5} & 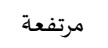 & $\% 78.2$ & 0.97 & 3.91 & 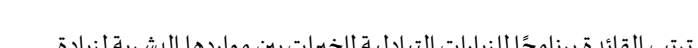 & 4 \\
\hline & & & & & ترتب القائدة برنامجَا للزيارات التبادلية للخبرات بين مواردها البشرية لزيادة & \\
\hline & & & & & الروابط الاجتماعية. & \\
\hline \multirow[t]{3}{*}{6} & 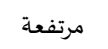 & $\% 77.8$ & 1.01 & 3.89 & توف القائر & 5 \\
\hline & & & & & 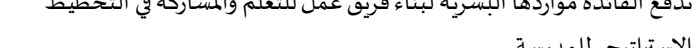 & \\
\hline & & & & & الاستراتيجي للمدرسة. & \\
\hline \multirow[t]{4}{*}{7} & مرتفعة & $\% 75.6$ & 1.00 & 3.78 & تعتمد القائدة ميدأ لمنظمات التحلمية التشاركية ف وضه خطط تنمة الموارد & 6 \\
\hline & & & & & 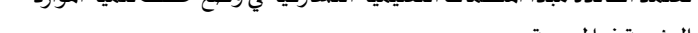 & \\
\hline & & & & & البشرية في المدرسة. & \\
\hline & مرتفعة & $\% 79.4$ & 0.81 & 3.97 & المحور الثالث ككل & \\
\hline
\end{tabular}

ويتضح من الجدول أعلاه أن عبارات المحور انحصرت انحصارًا كليَّا في درجة موافقة (مرتفعة)، حيث بلفت الدرجة الكلية لمتوسط المحور (3.97)، وانحراف معياري قدره (0.80)، وبوزن نسبي بلغ (79.4\%)؛ حيث كانت درجة المتوسط في المدى المتوسط (3.40-4.19)، وحققت العبارة رقم (2)،

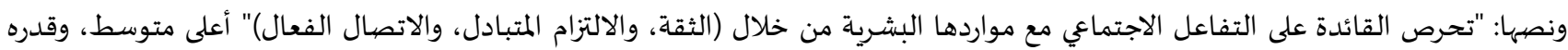
(4.14)، وبانحراف معياري قدره (0.86)، ووزن نسبي قدره (82.8\%). وترجع الباحثة ذلك إلى إنه قد يكون لحرص معظم قائدات المدارس على الشفافية والمصداقية في التعامل مع مواردها البشرية بإحداث التوازن بين البعد الإنساني والبعد العملي. واتفقت نتائج الدراسة الحالية مع نتائج دراسـة موثوني (Muthoni, 2015)، التي توصلت إلى عدد من الاقتراحات من قِبل المديرين والمعلمين لتحسين كفاءة الموارد البشرية، ومنها التواصل الفعال بعقد حوارات أسبوعية مع العاملين لتشجيع العلاقات الإنسانية.

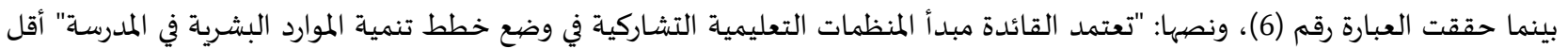

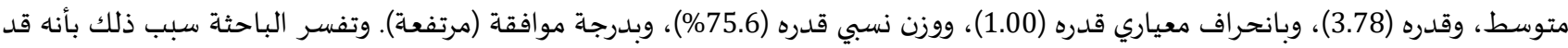

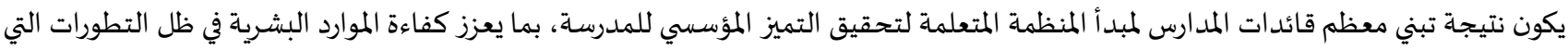

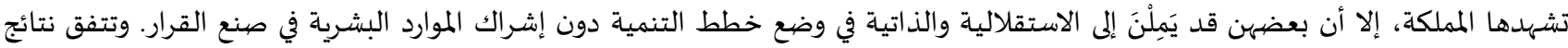

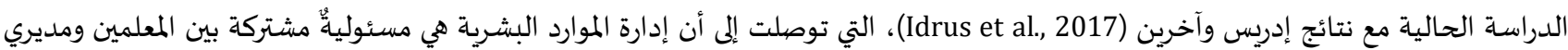

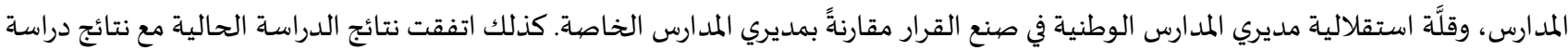

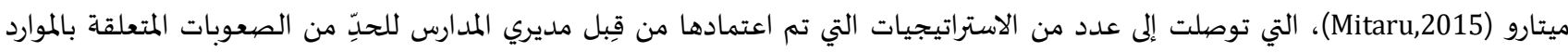
البشرية؛ منها: الاجتماعات التشاورية المنتظمة بين المديرين ومنسوبي المدرسة. 4.4. النتائج المتعلقة بالسؤال الر ابع: ما درجة إسهام قائدات المرحلة الابتدائية بالمدارس الحكومية بمدينة جدة في تنمية (المهارات التقنية) لدى في مواردها البشرية، في ضوء رؤية المملكة 2030، من وجهة نظر المعلمات والوكيلات؟

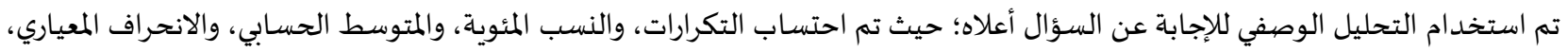

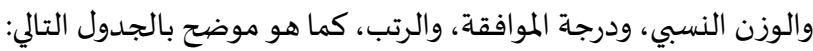


جدول(12): المتوسطات الحسابية والانحر افات المعيارية والترتيب لاستجابات أفراد العينة لعبارات المحور الثالث "تنمية المهارات التقنية" مرتبة تنازليًّا حسب متوسطات

\begin{tabular}{|c|c|c|c|c|c|c|}
\hline الرتب & المو افقة درجة & 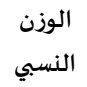 & الانحراف & المتوسط المسبي & الفقرات & العبارة - مقا \\
\hline 1 & مرتفعة & $\% 81.7$ & 0.84 & 4.09 & تحث القائدة مواردها البشرية على توظيف الأدوات والبرامج والتقنية الحديثة & 3 \\
\hline 2 & مرتفعة & $\% 80.8$ & 0.88 & 4.04 & 2030 تحرص القائدة على تهيئة بيئة تقنية حديثة من خلال رؤية مستقبلية تعزز رؤية & 1 \\
\hline 3 & مرتفعة & $\% 80.4$ & 0.96 & 4.02 & الشجع القائدة مواردها البشرية على التقنية الحديثة في التعاملات والاجتماعات & 6 \\
\hline 4 & مرتفعة & $\% 80.2$ & 0.92 & 4.01 & توجه القائدة مواردها البشرية إلى التعلم والتدريب الاحترافي في المجال الرقهي. & 2 \\
\hline 5 & مرتفعة & $\% 79.6$ & 0.91 & 3.98 & تستثمر القائدة أنظمة التعلم والتقنية الحديثة في استمرارية التنمية والتطوير. & 5 \\
\hline 6 & مرتفعة & $\% 79.4$ & 0.93 & 3.97 & تشجع القائدة مواردها البشرية على الاستفادة من المواقع والمصادر الرقمية في & 4 \\
\hline & مرتفعة & $\% 80.4$ & 0.80 & 4.02 & المحور الر ابع ككل & \\
\hline
\end{tabular}

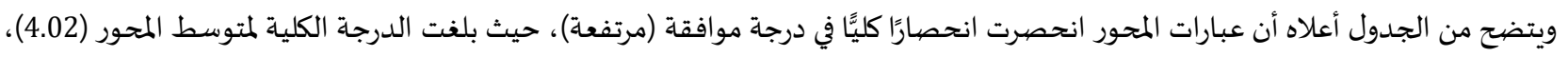

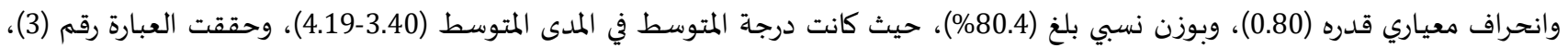

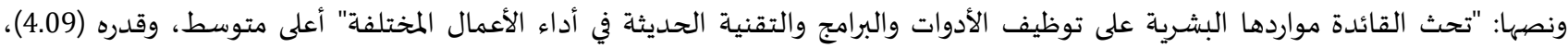

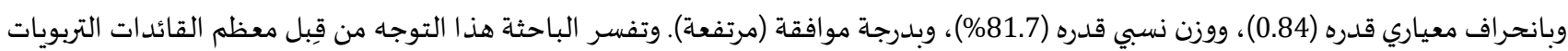

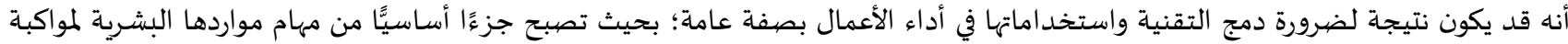

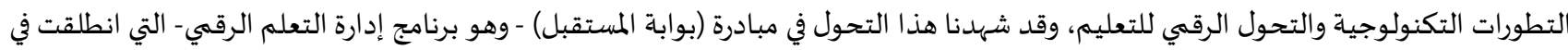

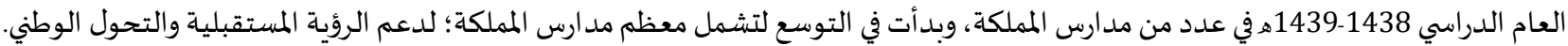

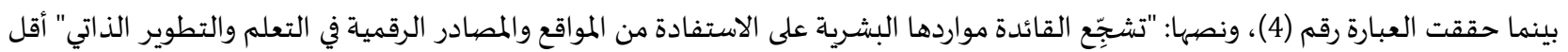

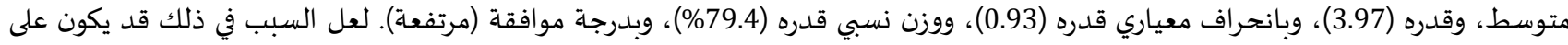

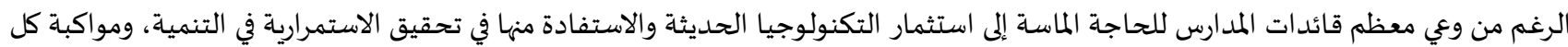

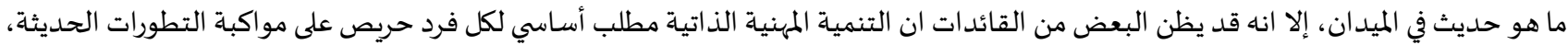
بالتالي ليس هناك حاجة ماسة إلى توجيه وتشجيع الموارد البشرية من قبل قائدة الممدرسة فيما يخص ذلان الكان.

5.4. النتائج المتعلقة بالسؤال الخامس: هل توجد فروق ذات دلالة إحصائية، بين اتجاهات مفردات العينة، في درجة إسهام قائدات المرحلة

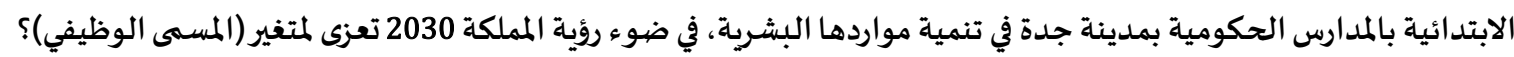

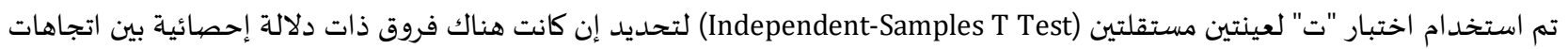
مفردات العينة نحو متوسطات محاور الاستبانة تبعًا لمتغير المسمى الوظيفي، كما هو موضح بالجدول التالي: جدول (13): نتائج اختبار"ت" لعينتين مستقلتين (Independent-Samples T Test) لتحديد إن كانت هناك فروق ذات دلالة إحصيائية بين اتجاهات مفردات العينة نحو متوسطات محاور الاستبانة تبعًا لمتغير المسنى الوظيفي

\begin{tabular}{|c|c|c|c|c|c|}
\hline الدرجة المعنوية & قيمة ت & الانحراف المعياري & المتوسط & المسسى الوظيفي & المحور \\
\hline \multirow[t]{2}{*}{0.11} & $1.56-$ & 0.79 & 3.95 & معلمة & تنمية المهارات المعرفية \\
\hline & & 0.87 & 4.14 & وكيلة & \\
\hline \multirow[t]{2}{*}{0.26} & 1.12 & 0.79 & 3.86 & معلمة & تنمية المهارات الأدائية \\
\hline & & 0.86 & 4.00 & وكيلة & \\
\hline \multirow[t]{2}{*}{0.15} & 1.44 & 0.80 & 3.95 & معلمة & تنمية المهارات الاجتماعية \\
\hline & & 0.83 & 4.12 & وكيلة & \\
\hline \multirow[t]{2}{*}{0.32} & 0.99 & 0.79 & 4.00 & معلمة & تنمية المهارات التقنية \\
\hline & & 0.85 & 4.12 & وكيلة & \\
\hline
\end{tabular}




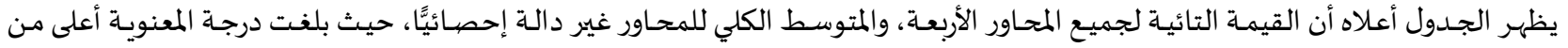

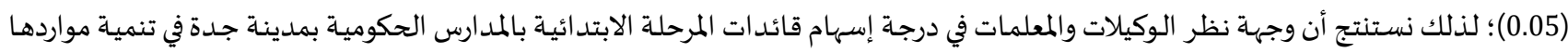
البشرية في ضوء رؤية المملكة 2030 لا تختلف، وجميعها في درجة موافقة (مرتفعة). واتفقت نتائج هذه الدراسة مع نتائج دراسـة مطرية (2016)، التي

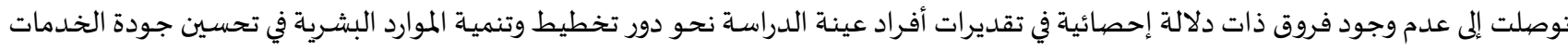

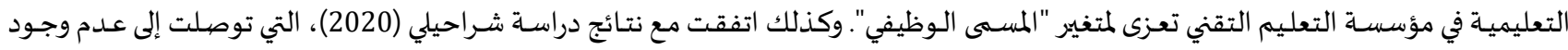

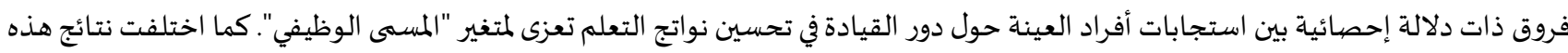

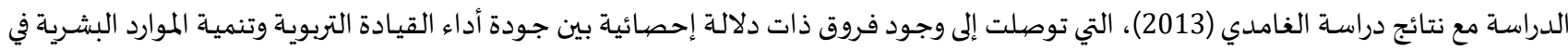
المدارس تعزى لمتغير "الوظيفة".

5.5. ملخص نتائج محاور الدراسـة:

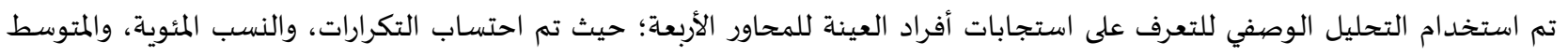

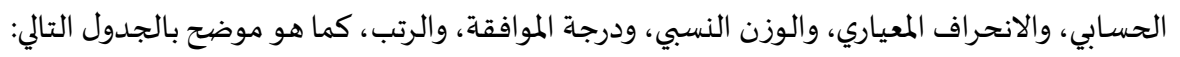

\begin{tabular}{|c|c|c|c|c|c|c|c|c|}
\hline للمتحاور للكبلي & للوكيلة الرتب & للمعلمة الرتب & المو افقة & النسبي & المعياري الانحراف & المتوسط & وكلمة/ & المحور \\
\hline \multirow{5}{*}{2} & & 2 & مرتفعة & $\% 79.06$ & 0.79 & 3.95 & معلمة & تنمية المهارات \\
\hline & 1 & & مرتفعة & \%82.87 & 0.87 & 4.14 & وكيلة & المعرفية \\
\hline & & & مرتفعة & $\% 77.8$ & 0.80 & 3.98 & الكلي & \\
\hline & & 3 & مرتفعة & $\% 77.20$ & 0.79 & 3.86 & معلمة & تنمية المهارات \\
\hline & 3 & & مرتفعة & $\% 79.91$ & 0.86 & 4.00 & وكيلة & الأدائية \\
\hline \multirow[t]{3}{*}{4} & & & مرتفعة & $\% 77.56$ & 0.80 & 3.88 & الكلي & \\
\hline & & 2 & مرتفعة & \%78.91 & 0.80 & 3.95 & معلمة & تنمية المهارات \\
\hline & 2 & & مرتفعة & $\% 82.40$ & 0.83 & 4.12 & وكيلة & الاجتماعية \\
\hline \multirow[t]{3}{*}{3} & & & مرتفعة & $\% 79.4$ & 0.80 & 3.97 & الكلي & \\
\hline & & 1 & مرتفعة & $\% 80.00$ & 0.79 & 4.00 & معلمة & تنمية المهارات \\
\hline & 2 & & مرتفعة & $\% 82.40$ & 0.85 & 4.12 & وكيلة & التقنية \\
\hline \multirow[t]{4}{*}{1} & & & مرتفعة & $\% 80.4$ & 0.80 & 4.02 & الكلي & \\
\hline & & & مرتفعة & $\% 78.79$ & 0.74 & 3.94 & معلمة & المتوسط الكلي \\
\hline & & & مرتفعة & $\% 81.90$ & 0.82 & 4.09 & وكيلة & للمحاور \\
\hline & & & مرتفعة & \%79.2 & 0,75 & 3,96 & الكلي & \\
\hline
\end{tabular}

نستخلص من الجداول أعلاه أن متوسطات المحاور الأربعة انحصرت انحصارًا كليًًا في درجة موافقة (مرتفعة)، حيث بلغت الدرجة الكلية لمتوسط

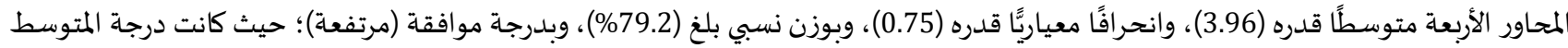

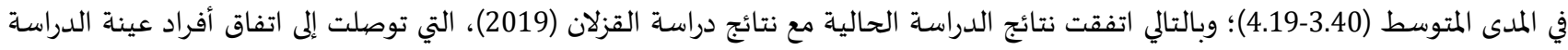
بدرجة (مرتفعة) حول إسهام القيادة التحويلية في تحقيق تنمية الموارد البشرية في ضوء رؤية 2030،وكذلك التهائ اتفقت مع نتائج دراسـة السرواني (2021)،

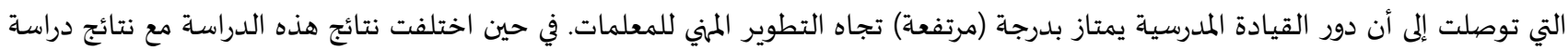

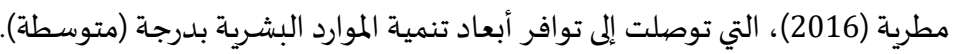
أما بالنسبة للمعلمات، فقد انحصرت بشكل كلي في درجة موافقة (مرتفعة)، حيث جاء في المرتبة الأولى محور "تنمية المهارات التقنية"، وجاء في

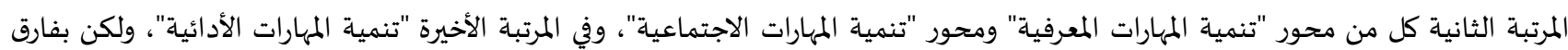

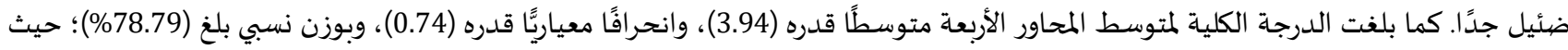
كانت درجة المتوسط في المدى المرتفع (3.40-4.19). أما بالنسبة للوكيلات، فقد انحصرت بشكل كلي في درجة موافقة (مرتفعة)، حيث جاء في المرتبة الأولى محور "تنمية المهارات المعرفية"، وجاء في

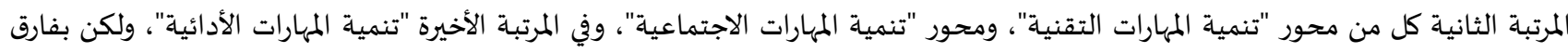

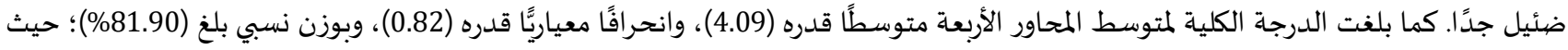
كانت درجة المتوسط في المدى المرتفع (3.40-4.19). 
ومما سبق يتضح أن الفروقات بين استجابات عينة الدراسة للمحاور الأبربعة غير ملحوظة وبسيطة جدًا، ومن ثم لا تؤثر في النتيجة الكلية لدرجة

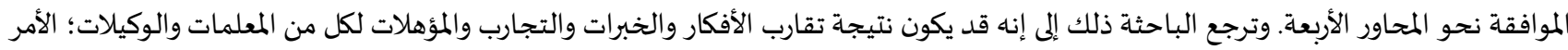
الذي جعلهن متقاربات في وجهات النظر نحو محاور الدراسة.

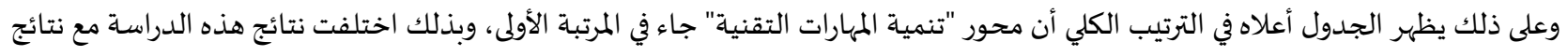

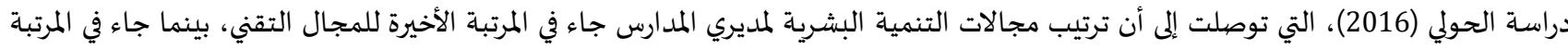

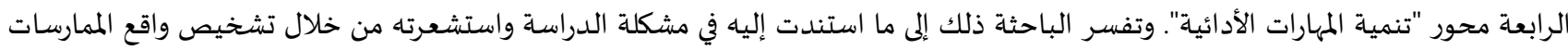

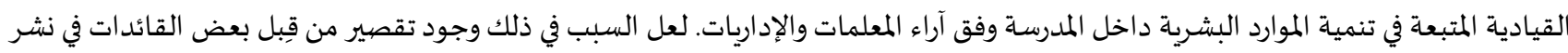

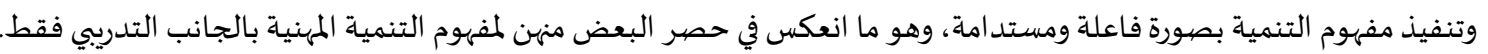

6.5. توصيات الدراسـة:

في ضوء النتائج التي توصلت إليها الدراسة، توصي الدية الباحثة بالتالي: أولاً: توصيات موجهة للقيادات التربوية:

استمرار دعم القيادات التربوية للتدريب والتعلم المستمر لمواردها البشرية، والاستفادة من العلوم والتقنيات الحديثة في تنمية المهارات المختلفة، من خلال الممارسات القيادية المساهمة في تحقيق ذلك (كما تم التطرق إليها في الاستبانة).

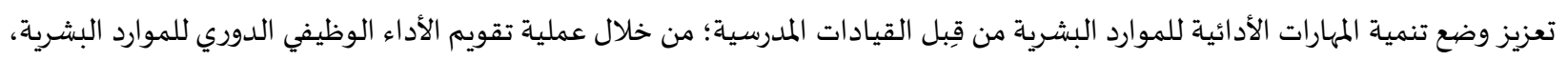
وتحليل جوانب القوة والضيعف للاستفادة منها مستقبليَّا في الخطط فئسئ التطويرية للأداء. ضرورة تجاوب قيادات المدرسة مع حاجات مواردها البشرية؛ بمنحهن دورًا مهمًّا في المشاركة باتخاذ القرار، والتخطيط للبرامج التنموية، والتشجيع على الإبداع والابتكار الدائم في العمل لتحقيق الجودة الشاملة.

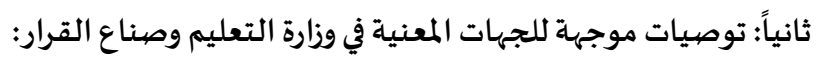

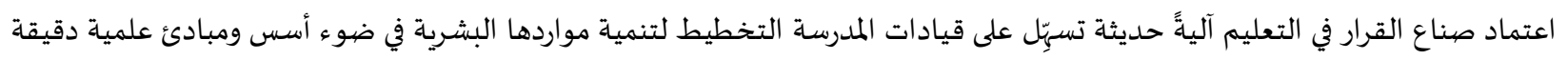

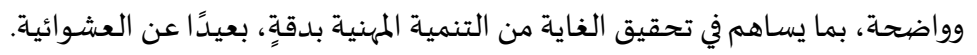
تركيز الجهات المسئولة في إدارة التعليم على مواكبة التطورات الحديثة والتحول الوطني؛ وذلك بتفعيل تكنولوجيا التعلم في التنمية والتطوير،

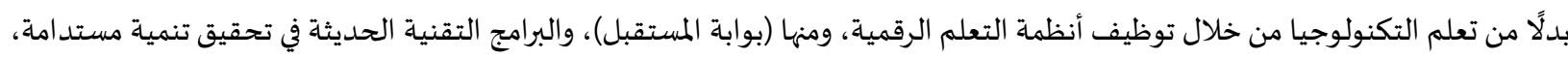
والاستفادة منها في إنجاز الأعمال بإبداعية لتحسين التحول نوفين الأداء والإنتاجية.

7.5 مقترحات الدراسـة: مقاسة: نظرًا لقلة الدراسـات التي تناولت مجال المواردات البشرادية في التعليم العام بالمملكة، وسعيًا إلى إثراء الميدان التربوي بمثل هذه الدراسـات، تقترح الباحثة القيام بدراسات في المواضيع التالية:

إجراء دراسـة بعنوان: درجة إسهام قيادات المد ارس الحكومية في تنمية مواردها البشرية في ضوء بورؤية المملكة 2030 من وجهاة نظر الإداريات. إجراء دراسة بعنوان: درجة توافر ممارسات إدارة الموارد البشرية لدى قيادات المدارس الخاصة. إجراء دراسة بعنوان: الصعوبات التي تعيق التخطيط الاستراتيجي في تنمية الموارد البشرية بالمد ارس وطرق علاجها.

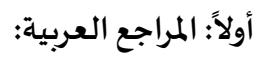

1. أحمد، محمد سمير (2009). الإدارة الاستواتيجية وتنمية الموارد البشرية. دار المسيرة للنشر والتوزيع. 2. 3. البدري، طارق (2001). الأساليب القيادية والإد/رية في المؤسسات التعليمية. دار الفكر للطباعة والنشر.

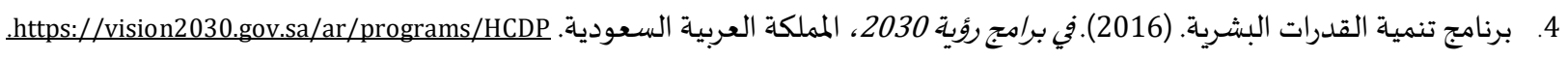
5. 6 6. توفيق، عبد الرحمن (2006). تحديد الاحتياجات التدريبية بين الهلدر والاستثمار (ط.2). مركز الخبرات المهنية للإدارة.

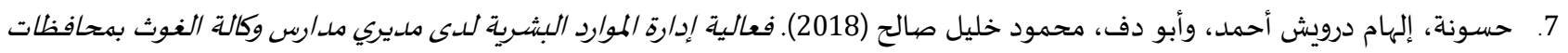
غزة وعلاقتها بمستوى أداء المعلمين (رسالة ماجستير غير منشورة). الجامعة دوفئ الإسلامية. 
8. الحسين، سارة عبد الله (2017). درجة ممارسة القيادة الإبداعية لدى قائدات مدارس المرحلة الابتدائية بمحافظة حوطة بن تميم (بحث ماجستير غير منشور). جامعة الإمام محمد بن سعود الإسلامية.

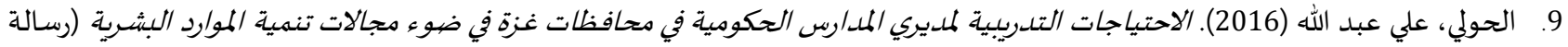
ماجستير غير منشورة). الجامعة الإسلامية.

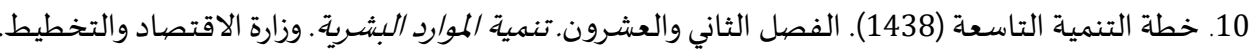

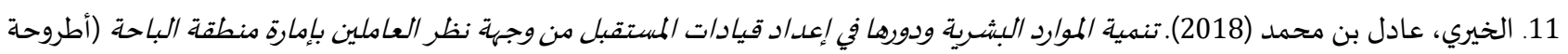
ماجستير غير منشورة). جامعة نايف العربية للعلوم الأمنية. 12. درة، عبد الباري إبراهيم (2003). تكنولوجيا الأداء البشري في المنظمات، الأسس النظرية ودلاعلاتها في البيئة العببية المعاصرة. المنظمة العبربية للتنمية الإدارية. 13. درويش، زينب عواد مفلح (2019). درجة ممارسة قائدات المدارس الثانوية بمحافظة الخرج للقيادة التشاركية وعلاقتها بفاعلية اتخاذ القرارات

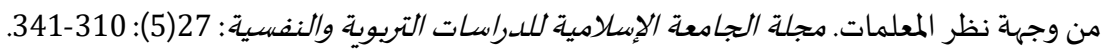

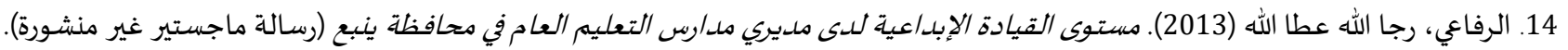
جامعة طيبة.

15. الرويس، عزيزة سعد. (2018). مستقبل تنمية القدرات البشرية في ضوء رؤية 2030. صحيفة الرياض.

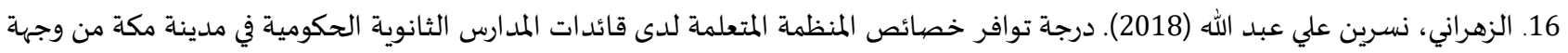
نظرهم. عالم التربية: (61): 14-50. 17. السالم، مؤيد سعيد، وصالح، عادل حرحوش (2002). إدارة الموارد البشرية-مدخل استراتيجي. عالم الكتب الحديث، جدار للكتاب العالمي للنشر والتوزيع.

18. السرحان، حسين أحمد (2014). التنمية البشرية المستدامة وبناء مجتمع المعرفة. مجلة أهل البيت عليهم السلام: (16): 138-155.

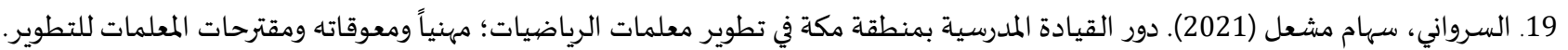

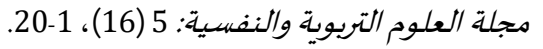
20. السلمي، علي (2005). ملامح الإدارة الجديدة في عصر المتعنيرات وانعكاساتها على إدارة التغيير (عرض ورقة). الملتقى الإداري الثالث-إدارة التطوير ومتطلبات التطوير في العمل الإداري، جدة، المملكة العربية السعودية.

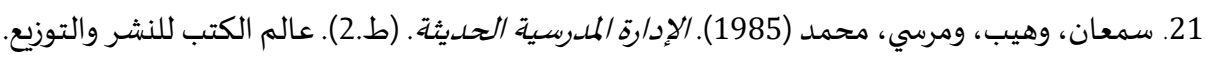
22. شراحيلي، جابر بن عبد الله (2020). دور القيادة المدرسية في تحسين نواتج التعلم وفق تصورات قادة المدارس ومشرفيها. مجلة دراسات عربية في التربية وعلم النفس: (118): 215-245. 23. شلتوت، أماني خضر (2009). تنمية الموارد البشـية كملدخل استراتيجي لوضع الاستثمار في العنصر البشـري: دراسة على موظفي الوكالة في قطاع غزة الرئاسة ومكتب غنة الإقليمي (رسالة ماجستير غير منشورة). الجامعة الإسلامياة.

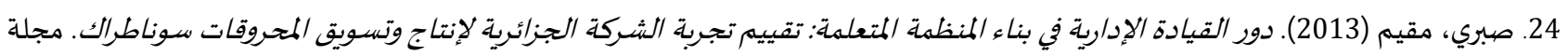
دراسات وأبحاث: (11): 147-162. 25. ضحاوي، بيومي محمد، وخاطر ، محمد إبراهيم (2014). رؤى معاصهة في إدارة المؤسسات التعليمية. دار الفكر العربي. 26. عبيدات، ذوقان، عبد الحق، كايد، وعدس، عبد الرحمن (2016). البحث العلمي-مفهومهه وأدواته وأساليبه. (ط.18). داريه دار الفكر للنشر والتوزيع.

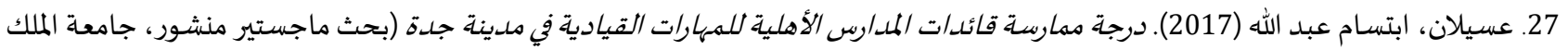

عبد العزيز). شبكة الألوكة. 28. الغامدي، علي بن محمد بن زهيد (2013). درجة جودة أداء القيادة التوبوية وتنمية الموارد البشرية في المدارس الثانوية والمتوسطة بالمدينة المنورة. مجلة العلوم التوبوية: 1068-1066-1096.

29. فاطمة الزهراء، عبيدي، وعرايبية، محمد (2018). تثمين رأس المال الفولية الفكري داخل الجامعة ودوره في تجسيد إدارة المعرفة دراسة ميدانية بجامعة

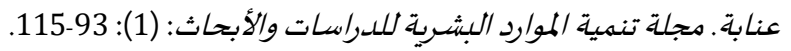

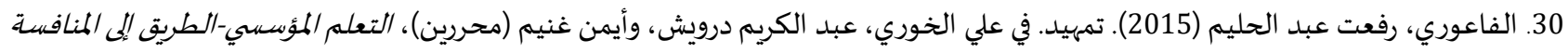
والتطورفي القرن الحادي والعشبين (ص 10-20). منشورات المنظمة العبية للتنمية الإدارية. 31. القحطاني، سالم سعيد (2016). القيادة الإد/رية: التحول نحو نموذج القيادي العالمي (ط.3. (3). مكتبة المتنبي. 
32. القزلان، منى محمد علي (2019). القيادة التحويلية ودورها في تنمية الموارد البشرية في ضوء رؤية المملكة 2030: من وجهة نظر الضباط بكليتي

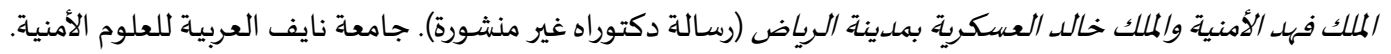

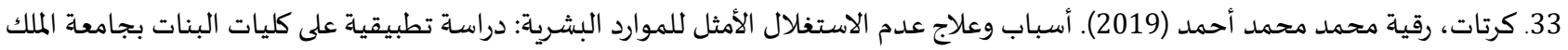

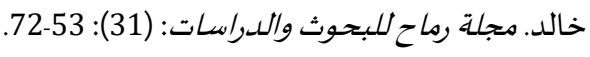

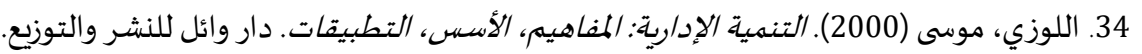

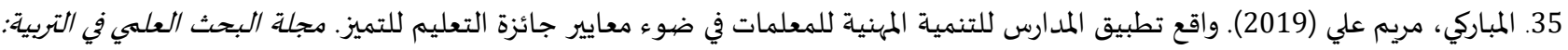
.501-459: (20)9

36. محمد، جاسم محمد (2008). سيكولوجية الإد/رة التعليمية والملدرسية وآفاق التطوير العام. دار الثقافة للنشر والتوزيع.

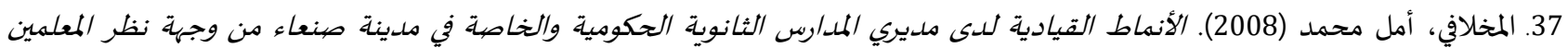
وعلاقتهما برضاهم الوظيفي (رسالة ماجستير غير منشورة). جامعة الشرق الأوسط للدراسات العليا. 38. مطرية، باسم جميل (2016). دور تخطيط وتنمية الموارد البشرية في تحسين جودة الخدادمات التعليمية في مؤسسات التهات التعليم التقني (رسالة ماجستير غير منشورة)، أكاديمية الإدارة السياسية للدراسات العليا وجامعة الأقصى. بأسئ.

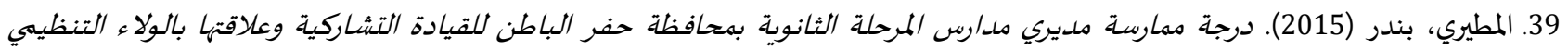

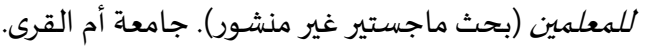

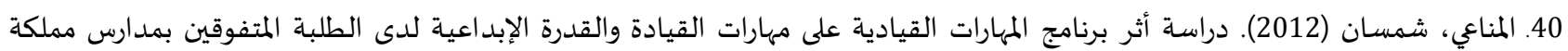
البحرين. مجلة الدراسيات النفسية: 20 (4): 456-466.

41. منصهوري، كمال، وصولح، سماح (2010). تسيير الكفاء/ت الإطار المفاهيهي والمجالات الكبرى. أبحاث اقتصادية وإد/رية: (7): 49-69.

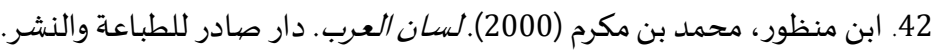
43. ابن منظور، محمد بن مكرم (2003).لسعان العـب. دار مار الكتب العلمياة.

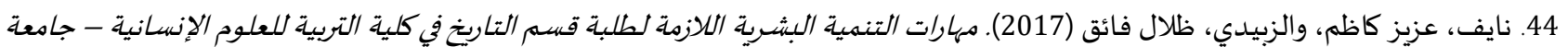
كربلاء من وجهة نظرهم. مجلاة أهل البيت عليهم السلام: (18): 45-99.

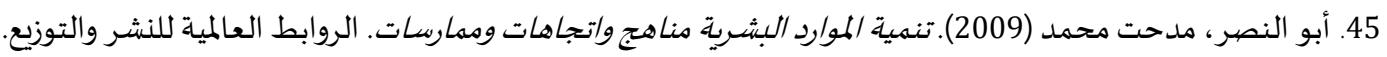
46. الهباش، أسامة محمد (2002). المشككلات التي تواجه الملديرين الجدد في مدارس محافظات غزة وسبل مواجهتها ( رسالة ماجستير غير منشورة)، الجامعة الإسلامية.

47. وزارة التعليم (1440). الدليل التنظيمي لمدارس التعليم العام-الإصبد/ر الرابع. وزارة التعليم.

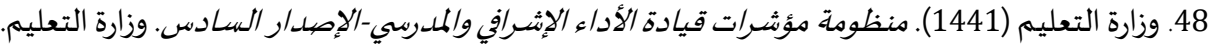

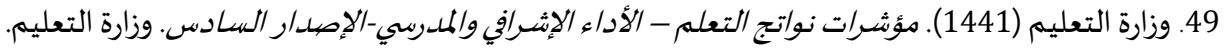

\section{ثانيًا: المراجع الأجنبية:}

1. Idrus, N., Othman, A., \& Faizuddin, A. (2017). The Practices of Human Resource Management among Headmasters in Primary Schools: A Case Study of Selected National and Private Schools in Malaysia. Journal of Educational Studies, 5 (1): 26-48. https://doi.org/10.31436/ijes.v5i1.149

2. Iqbal, M. (2012). Strategy of Improving the Leadership Skills for the Schools Managers at Khyber Pakhtunkhwa (Unpublished Master's Thesis). International Islamic University.

3. Jolley, H. (2016). Transformative Leaders: A mixed-Methods Study of the Role of Transformational Leadership and its Impact on Teacher Efficacy (Unpublished doctoral dissertation). Garden-Webb University.

4. Mitaru, G. (2015). Barriers to Effective Human Resource Management Faced by Public Primary School Head teachers: Mwea East Sub-County, Kirinyaga County-Kenya(Unpublished Master's Thesis). Kenyatta University.

5. Muthoni, N. (2015). Effectiveness of Secondary School Principals in Management of Human Resources: A Case of Mathioya District, Murang'a County, Kenya (Unpublished Master's Thesis). Kenyatta University.

6. Ombura, N. (2017). Assessment of Human Resource Management Practices and Performance of Private Primary Schools in Homa Bay County, Kenya (Unpublished Master's Thesis). Maseno University. 
المجلة الدولية للدراسـات التربوية والنفسية

International Journal of Educational \& Psychological Studies (EPS)

Journal Homepage: https://www.refaad.com/views/EPSR/Home.aspx

www.refaad.com

ISSN: 2520-4149 (Online) 2520-4130 (Print)

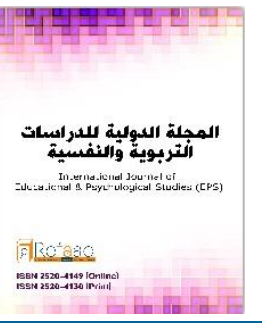

\title{
The degree of contribution of the public primary school leaders in Jeddah city in developing their human resources in the light of kingdom's vision 2030 (from the female teachers and the deputy superintendent point of view)
}

\author{
Hanan Mahmoud Sami Ahmed Arab \\ MA in Educational Leadership, Educational Policies and Evaluation, Dar Al-Hekma University, KSA \\ hananarab.sa@gmail.com
}

Aisha Bakr Adam Fallath

Professor of Educational Administration and Planning, College of Health and Behavioral Sciences and Education, Dar Al-Hekma University, KSA

Received : 2/6/2021 Revised : 15/6/2021 Accepted : 10/7/2021 DOI : https://doi.org/10.31559/EPS2021.10.2.12

Abstract: This study aims at measuring the degree to which the female leaders of public primary schools in the city of Jeddah have contributed to developing their human resources in the light of the Kingdom's Vision 2030 from the viewpoint of female teachers and deputy superintendent.

The study used the survey-descriptive method, and a questionnaire was conducted as a tool to collect data regarding the contributing practices made by the female school leaders of public primary schools to develop the (cognitive, performance, social, and technological) skills of their human resources.

The study sample consisted of 383 female teachers and deputy superintendent, who were chosen by the simple random method.

The results show that the degree to which the primary stage female school leaders have contributed in developing their human resources from the viewpoint of the sample's individual was in a (high) degree of consent with an arithmetic average (3.96), and a percentage (79.2\%).

In addition, there were no differences of statistical significance in the average rate of responses of the sample's people regarding the study themes.

The major recommendations concluded by the study are enhancing the status of developing performance skills of human resources by school leaders through the process of regular job performance evaluation of the human resources, analyzing strengths and weaknesses to utilize them in the future performance development plans, and urging education decision makers to adopt a modern mechanism to help the school leaders develop development plans for their human resources based on precise and clear scientific principles, which will contribute to achieve the purpose of professional development in an accurately way that avoids randomness.

Keywords: educational leadership; management; modern leadership styles; professional development.

\section{References:}

1. 'bydat, Dwqan, 'bd Alhq, Kayd, W'ds, 'Ebd Alrhmn (2016). Albhth Al'lmy-Mfhwmh Wadwath Wasalybh. (T.18). Dar Alfkr Llnshr Waltwzy'.

2. 'sylan, Abtsam 'bd Allh (2017). Drjt Mmarsh Qa'dat Almdars Alahlyh Llmharat Alqyadyh Fy Mdynt Jdh (Bhth Majstyr Mnshwr, Jam't Almlk 'bd Al'zyz). Shbkt Alalwkh.

3. Ahmd, Mhmd Smyr (2009). Aledarh Alastratyjyh Wtnmyh Almward Albshryh. Dar Almsyrh Llnshr Waltwzy'.

4. Albdry, Tarq (2001). Alasalyb Alqyadyh Waledaryh Fy Alm'ssat Alt'lymyh. Dar Alfkr Lltba'h Walnshr.

5. Brnamj Tnmyh Alqdrat Albshryh. (2016). Fy Bramj R'yt 2030, Almmlkh Al'rbyh Als'wdyh. https://vision2030.gov.sa/ar/programs/hcdp.

6. Dhawy, Bywmy Mhmd, Wkhatr, Mhmd Ebrahym (2014). R'a M'asrh Fy Edart Alm'ssat Alt'lymyh. Dar Alfkr Al'rby. 
7. Drh, 'bd Albary Ebrahym (2003). Tknwlwjya Alada' Albshry Fy Almnzmat, Alass Alnzryh Wdlalatha Fy Alby'h Al'rbyh Alm'asrh. Almnzmh Al'rbyh Lltnmyh Aledaryh.

8. Drwysh, Zynb 'wad Mflh (2019). Drjt Mmarsh Qa'dat Almdars Althanwyh Bmhafzt Alkhrj Llqyadh Altsharkyh W'laqtha Bfa'lyt Atkhad Alqrarat Mn Wjht Nzr Alm'lmat. Mjlt Aljam'h Aleslamyh Lldrasat Altrbwyh Walnfsyh: 27(5): 310-341.

9. Aledarh Al'amh Llt'lym Bmhafzh Jdh (1440/1441). Byan Ehsa'y Hsb Altshkylat Almdrsyh. Alsh'wn Alt'lymyh-Bnat.

10. Alfa'wry, Rf't 'bd Alhlym (2015). Tmhyd. Fy 'ly Alkhwry, 'bd Alkrym Drwysh, Waymn Ghnym (Mhrryn), Alt'lm Alm'ssyAltryq Ela Almnafsh Walttwr Fy Alqrn Alhady Wal'shryn (S 10-20). Mnshwrat Almnzmh Al'rbyh Lltnmyh Aledaryh.

11. Fatmh Alzhra', 'bydy, W'raybyh, Mhmd (2018). Tthmyn Ras Almal Alfkry Dakhl Aljam'h Wdwrh Fy Tjsyd Edarh Alm'rfh Drash Mydanyh Bjam't 'nabh. Mjlt Tnmyt Almward Albshryh Lldrasat Walabhath: (1): 93-115.

12. Alghamdy, 'ly Bn Mhmd Bn Zhyd (2013). Drjt Jwdh Ada' Alqyadh Altrbwyh Wtnmyh Almward Albshryh Fy Almdars Althanwyh Walmtwsth Balmdynt Almnwrh. Mjlt Al'lwm Altrbwyh: 40: 1068-1096.

13. Hswnh, Elham Drwysh Ahmd, Wabw Df, Mhmwd Khlyl Salh (2018). F'alyt Edart Almward Albshryh Lda Mdyry Mdars Wkalt Alghwth Bmhafzat Ghzh W'laqtha Bmstwa Ada' Alm'Imyn (Rsalt Majstyr Ghyr Mnshwrh). Aljam'h Aleslamyh.

14. Alhsyn, Sarh 'bd Allh (2017). Drjt Mmarsh Alqyadh Alebda'yh Lda Qa'dat Mdars Almrhlh Alabtda'yh Bmhafzt Hwth Bn Tmym (Bhth Majstyr Ghyr Mnshwr). Jam't Alemam Mhmd Bn S'wd Aleslamyh.

15. Alhwly, 'ly 'bd Allh (2016). Alahtyajat Altdrybyh Lmdyry Almdars Alhkwmyh Fy Mhafzat Ghzh Fy Dw' Mjalat Tnmyt Almward Albshryh (Rsalt Majstyr Ghyr Mnshwrh). Aljam'h Aleslamyh.

16. Khth Altnmyh Altas'h (1438). Alfsl Althany Wal'shrwn. Tnmyt Almward Albshryh. Wzart Alaqtsad Waltkhtyt.

17. Alkhyry, 'adl Bn Mhmd (2018). Tnmyt Almward Albshryh Wdwrha Fy E'dad Qyadat Almstqbl Mn Wjht Nzr Al'amlyn Bemart Mntqt Albahh (Atrwht Majstyr Ghyr Mnshwrh). Jam't Nayf Al'rbyh Ll'lwm Alamnyh.

18. Alrfa'y, Rja Allh 'ta Allh (2013). Mstwa Alqyadh Alebda'yh Lda Mdyry Mdars Alt'lym Al'am Fy Mhafzt Ynb' (Rsalt Majstyr Ghyr Mnshwrh). Jam't Tybh.

19. Alrwys, 'zyzh S'd. (2018). Mstqbl Tnmyh Alqdrat Albshryh Fy Dw' R'yt $2030 . \quad$ Shyfh Alryad. http://www.alriyadh.com/1728208.

20. Alsalm, M'yd S'yd, Wsalh, 'adl Hrhwsh (2002). Edart Almward Albshryh-Mdkhl Astratyjy. 'alm Alktb Alhdyth, Jdar Llktab Al'almy Llnshr Waltwzy'.

21. Sbry, Mqym (2013). Dwr Alqyadh Aledaryh Fy Bna' Almnzmh Almt'lmh: Tqyym Tjrbt Alshrkh Aljza'ryh Lentaj Wtswyq Almhrwqat Swnatrak. Mjlt Drasat Wabhath: (11): 147-162.

22. Shrahyly, Jabr Bn 'bd Allh (2020). Dwr Alqyadh Almdrsyh Fy Thsyn Nwatj Alt'lm Wfq Tswrat Qadh Almdars Wmshrfyha. Mjlt Drasat 'rbyh Fy Altrbyh W'Im Alnfs: (118): 215-245.

23. Shltwt, Amany Khdr (2009). Tnmyt Almward Albshryh Kmdkhl Astratyjy Lwd' Alastthmar Fy Al'nsr Albshry: Drash 'la Mwzfy Alwkalh Fy Qta' Ghzh Alr'ash Wmktb Ghzh Aleqlymy (Rsalt Majstyr Ghyr Mnshwrh). Aljam'h Aleslamyh.

24. Alslmy, 'ly (2005). Mlamh Aledarh Aljdydh Fy 'sr Almtghyrat Wan'kasatha 'la Edart Altghyyr ('rd Wrqh). Almltqa Aledary Althalth-Edarh Alttwyr Wmttlbat Alttwyr Fy Al'ml Aledary, Jdh, Almmlkh Al'rbyh Als'wdyh.

25. Sm'an, Whyb, Wmrsy, Mhmd (1985). Aledarh Almdrsyh Alhdythh. (T.2). 'alm Alktb Llnshr Waltwzy'.

26. Alsrhan, Hsyn Ahmd (2014). Altnmyh Albshryh Almstdamh Wbna' Mjtm' Alm'rfh. Mjlt Ahl Albyt 'lyhm Alslam: (16): 138155.

27. Alsrwany, Sham Msh'l (2021). Dwr Alqyadh Almdrsyh Bmntqh Mkh Fy Ttwyr M'lmat Alryadyat: Mhnyaan Wm'wqath Wmqtrhat Alm'Imat Llttwyr. Mjlt Al'Iwm Altrbwyh Walnfsyh: 5 (16), 1-20.

28. Altab'y, Mhmd Kaml (2006). Altnmyh Albshryh Almstdamh: Almfhwm Walmkwnat. Almrkz Aldwly Lldrasat Almstqblyh Walastratyjyh.

29. Twfyq, 'bd Alrhmn (2006). Thdyd Alahtyajat Altdrybyh Byn Alhdr Walastthmar (T.2). Mrkz Alkhbrat Almhnyh Lledarh.

30. Alzhrany, Nsryn 'ly 'bd Allh (2018). Drjt Twafr Khsa's Almnzmh Almt'lmh Lda Qa'dat Almdars Althanwyh Alhkwmyh Fy Mdynt Mkh Mn Wjht Nzrhm. 'alm Altrbyh: (61): 14-50. 